\title{
Heparin-containing block copolymers
}

\section{Part I Surface Characterization}

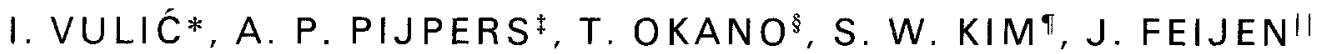 \\ Biomaterials Section, Department of Chemical Technology, University of Twente, \\ PO Box 217, 7500 AE Enschede, The Netherlands \\ ${ }^{\ddagger} D S M$ Research, PO Box 18, 6160 MD Geleen, The Netherlands \\ ${ }^{\S}$ Tokyo Women's Medical College, 8-1 Kawada-Cho, Shinjuku-ku, Tokyo, Japan \\ "Center for Controlled Chemical Delivery and Department of Pharmaceutics, \\ University of Utah, Salt Lake City, UT 84112, USA
}

\begin{abstract}
Newly synthesized heparin-containing block copolymers, consisting of a hydrophobic block of polystyrene (PS), a hydrophilic spacer-block of poly (ethylene oxide) (PEO) and covalently bound heparin (Hep) as bioactive block, were coated on aluminium, glass,

polydimethylsiloxane (PDMS), PS or Biomer substrates. Surfaces of coated materials were characterized by transmission electron microscopy (TEM), contact angle measurements and $X$-ray photoelectron spectroscopy for chemical analysis (XPS). It was demonstrated by TEM that thin films of PS-PEO and PS-PEO-Hep block copolymers consisted of heterogeneous microphase separated structures. Using sessile-drop and Wilhelmy plate dynamic contact angle measurements, insight was provided into the hydrophilicity of the surfaces of the coatings. Measurements with hydrated coatings of PS-PEO and PS-PEO-Hep block copolymers revealed that the surfaces became more hydrophilic during immersion in water, due to relaxation/reorientation, or swelling of PEO or PEO-Hep domains, respectively. XPS results for PS, PEO, heparin and PS-PEO as powder agreed well with qualitative and quantitative predictions. XPS results for films of PS-PEO and PS-PEO-Hep block copolymers showed enrichments of PEO in the top layers of the coatings. This effect was more pronounced for hydrated surfaces. Only small amounts of heparin were detected at the surface of coatings of PS PEO Hep block copolymers.
\end{abstract}

\section{Introduction}

The surface characteristics of biomaterials that are applied in contact with blood have been studied extensively [1]. The aim has been to derive relationships between the surface properties of the material and the interaction of the biomaterial with the biological environment [2-4]. We have developed new antithrombogenic coatings, using ABC-type block copolymers consisting of a hydrophobic block (A), a hydrophilic spacer (B) and a bioactive heparin (C) [5-7]. The antithrombogenicity of these coatings will be closely related to the availability of heparin at the surface. Because these ABC-type block copolymers contain mutually incompatible segments, it is hypothesized that coatings of these block copolymers prepared by dip coating will exhibit a heterogeneous microphase separated surface structure. This microphase separated structure may show an enrichment of one of the phases at the surface. The surface morphology will be governed by the chemical structure of the block copolymer, the molecular weights of the blocks, the extent of phase separation (e.g. the thermal and physical history, casting solvent and temperature), the difference in surface free energy between different components and/or the exposure to different environments.

Grainger et al. [8] demonstrated that surfaces of coatings of amphiphilic block copolymers of PS-PEO and of PDMS, PEO and Hep (PDMS-PEO-Hep) were heterogeneous with different amounts of hydrophilic and hydrophobic constituents present. The PS-PEO block copolymers showed spherical domains of PEO in a matrix of PS, whereas PDMS-PEO-Hep block copolymers formed irregular lattice-type networks of PEO/Hep in a matrix of PDMS.

With contact angle measurements, insight is provided into the hydrophilicity of coated surfaces. A contact angle measurement technique, such as the Wilhelmy plate (air-water-polymer system), is a powerful method of detecting changes in the surface properties brought about by reorientation of polymer chains or segments of the polymers at the interface, under the influence of the local adjacent phase [9]. TEM is a suitable method for the characterization of the morphological structure of copolymers. With this

\footnotetext{
* Present address: DSM Research, PO Box 18, 6160 MD Geleen, The Netherlands.

"Author to whom all correspondence should be addressed.
} 
technique it is possible to resolve structural components, such as different domains in polymeric materials [10]. The application of XPS can provide detailed information about the topography and composition in the top layer of a few nm of the surface $[8,11-14]$.

For the application of the block copolymers as an antithrombogenic coating, both the surface properties of the coating as a function of the substrate and the biological availability of the heparin moiety on the surface of the coating are important. In this paper the surface characteristics of heparin-containing block copolymers, coated on aluminium, glass, PDMS, PS or polyurethane (Biomer) are described. Part II of this series will deal with the blood compatibility of coated surfaces.

\section{Materials and methods}

$\gamma$-Aminopropyltriethoxysilane (GAPTS; Janssen Chimica, Beerse, Belgium), anhydrous sodium chromate $\mathrm{Na}_{2} \mathrm{CrO}_{4}$; BDH Laboratory Chemicals, Poole, UK), heparin, sodium salt (Hep) from porcine mucosa with a specific activity of $165 \mathrm{U} \mathrm{mg}^{-1}$, as indicated by the manufacturer (Diosynth BV, Oss, The Netherlands), $65 \%$ nitric acid $\left(\mathrm{HNO}_{3}\right.$; Merck, Darmstadt, Germany) and the solvents chloroform (Janssen Chimica), $N, N$-dimethyl acetamide (DMAc; Merck), ethanol (Merck), methanol (Merck), tetrahydrofuran (THF; Merck) and toluene (Merck) were used as received.

Nitrous acid-degraded heparin was prepared as described previously [15], having a specific activity of $65 \mathrm{U} \mathrm{mg}^{-1}$.

Amino-telechelic PEO with molecular weight 4000 $\left[\mathrm{H}_{2} \mathrm{~N}-\mathrm{PEO}(4000)-\mathrm{NH}_{2}\right]$ was a generous gift from Nippon Oil and Fats Co. Ltd (Ibaraki, Japan) and was characterized as described previously [5]. $N, N$ Dimethylformamide (DMF; Merck) was distilled under nitrogen at reduced pressure, after drying over anhydrous magnesium sulphate $\left(100 \mathrm{~g}^{-1}\right)$ and the fraction of boiling point $65^{\circ} \mathrm{C}$ at $39 \mathrm{mmHg}$ pressure was used.

PS-PEO diblock copolymers were synthesized by a coupling reaction of $\mathrm{PS}-\mathrm{NH}_{2}$ (prepared by radical or

TABLE I Characterization of materials used

\begin{tabular}{|c|c|c|c|c|c|}
\hline \multirow[t]{2}{*}{ Code } & \multicolumn{2}{|l|}{ PS } & \multirow{2}{*}{$\begin{array}{l}\text { PEO } \\
M_{n}\end{array}$} & \multicolumn{2}{|c|}{ Hep-NADHep } \\
\hline & Synthesis & $M_{n}$ & & Coupling & $M_{n}$ \\
\hline $\mathrm{PS}_{0} \mathrm{E}_{1}$ & Radical & 3300 & 500 & & \\
\hline $\mathrm{PS}_{1} \mathrm{E}_{2}$ & Anionic & 8500 & 4000 & & \\
\hline $\mathrm{PS}_{2} \mathrm{E}_{2}$ & Radical & 9300 & 4000 & & \\
\hline $\mathrm{PS}_{4} \mathrm{E}_{2}$ & Radical & 15700 & 4000 & & \\
\hline $\mathrm{PS}_{5} \mathrm{E}_{2}$ & Anionic & 23000 & 4000 & & \\
\hline $\mathrm{PS}_{0} \mathrm{E}_{1} \mathrm{H}_{1}$ & Radical & 3300 & 500 & EDC & 11000 \\
\hline $\mathrm{PS}_{2} \mathrm{E}_{2} \mathrm{H}_{1}$ & Radical & 9300 & 4000 & EDC & 11000 \\
\hline $\mathrm{PS}_{5} \mathrm{E}_{2} \mathrm{H}_{1}$ & Anionic & 23000 & 4000 & EDC & 11400 \\
\hline $\mathrm{PS}_{1} \mathrm{E}_{2} \mathrm{H}_{2}$ & Anionic & 8500 & 4000 & $\mathrm{NaBH}_{3} \mathrm{CN}$ & 6000 \\
\hline $\mathrm{PS}_{5} \mathrm{E}_{2} \mathrm{H}_{2}$ & Anionic & 23000 & 4000 & $\mathrm{NaBH}_{3} \mathrm{CN}$ & 6000 \\
\hline
\end{tabular}

${ }^{\text {a }}$ PS, amino-semitelechelic polystyrene; PEO, amino-telechelic poly(ethylene oxide); Hep, native heparin $\left(\mathrm{H}_{1}\right)$; and NADHep, nitrous acid-degraded heparin $\left(\mathrm{H}_{2}\right)$. For characterization methods see [5-7]. anionic polymerization) with $\mathrm{H}_{2} \mathrm{~N}-\mathrm{PEO}-\mathrm{NH}_{2}$, using toluene 2,4-diisocyanate as coupling agent, according to the procedures described previously [5-7].

PS-PEO-Hep block copolymers were synthesized by (a) coupling of PS-PEO- $\mathrm{NH}_{2}$ with heparin, performed in a DMF $-\mathrm{H}_{2} \mathrm{O}(40: 1, \mathrm{v} / \mathrm{v})$ mixture, by first activating carboxylic acid groups of heparin with 1-ethyl-3-(3-dimethylaminopropyl)carbodiimide and subsequently reacting the activated carboxylic acid groups with amino groups of PS-PEO- $\mathrm{NH}_{2}$, as described in [5], and (b) coupling of PS-PEO- $\mathrm{NH}_{2}$ with nitrous acid-degraded heparin performed in a $\mathrm{DMF}-\mathrm{H}_{2} \mathrm{O}(40: 1, \mathrm{v} / \mathrm{v})$ mixture, using cyanoborohydride as reducing agent, also as described previously $[6,7]$.

The properties of the polymeric materials used are summarized in Table $\mathbf{I}$.

\subsection{Preparation of coatings of the block copolymers on different substrates}

\subsubsection{Coatings for TEM}

Thin films of block copolymers (approximately $1.5 \mu \mathrm{m})$ were prepared by pouring $10 \mu 10.5 \%(\mathrm{w} / \mathrm{v})$ $\mathrm{DMF}-\mathrm{H}_{2} \mathrm{O}(40: 1, \mathrm{v} / \mathrm{v})$ solutions on carbon-coated electron microscope copper grids (diameter $3.05 \mu \mathrm{m}$ ) and evaporating the solvents in a nitrogen stream at ambient temperature overnight.

\subsubsection{Coatings for contact angle measurements}

Aluminium foil was first cleaned by treatment with sandpaper. After cleaning in an ultrasonic bath three times with doubly distilled water for $1 \mathrm{~min}$, three times with ethanol for $1 \mathrm{~min}$ and three times with hexane for $1 \mathrm{~min}$, the aluminium foil was dried in a nitrogen stream and cut into pieces of approximately $10 \mathrm{~mm} \times 20 \mathrm{~mm}$.

Thin coatings of block copolymers (approximately $2.5 \mu \mathrm{m}$ ) were prepared by applying $50 \mu \mathrm{l}$ from a $10 \%$ $(\mathrm{w} / \mathrm{v}) \mathrm{DMF}-\mathrm{H}_{2} \mathrm{O}(40: 1, \mathrm{v} / \mathrm{v})$ solution on the flat aluminium substrates. The coatings were dried in a nitrogen stream at ambient temperature overnight.

Microscope glass coverslips (type no. 1, $24 \mathrm{~mm}$ $\times 50 \mathrm{~mm}$; Propper, Smethwich, Warley, UK) were cleaned by treatment with $5 \%$ (w/v) $\mathrm{Na}_{2} \mathrm{CrO}_{4}$ in $\mathrm{HNO}_{3}$. After washing three times with doubly distilled water and twice with methanol, the glass coverslips were dried in an oven at $120^{\circ} \mathrm{C}$ overnight.

To obtain block copolymer coatings on bare glass surfaces, clean glass coverslips were coated by slow, uniform dipping into $2 \%(\mathrm{w} / \mathrm{v})$ solutions of block copolymers in DMF- $\mathrm{H}_{2} \mathrm{O}(40: 1, \mathrm{v} / \mathrm{v})$. These were then placed vertically in an oven at $37^{\circ} \mathrm{C}$. After $6 \mathrm{~h}$ the coated coverslips were vacuum-dried overnight.

Coatings on PS surfaces were obtained by initially precoating the glass coverslips with a solution of PS, followed by coating with solutions of block copolymers as described above. First the clean glass coverslips were treated with a solution of $5 \%$ (w/v) GAPTS in toluene for $4 \mathrm{~h}$. After washing once with toluene, four times with ethanol and once with water (no 
visible droplet of water was detected on the surfaces), the treated coverslips were dried in an oven at $120^{\circ} \mathrm{C}$ overnight. These silanized coverslips were then precoated with a $2 \%(\mathrm{w} / \mathrm{v})$ solution of PS (BASF KR 2521; Ludwigshafen, Germany) in chloroform. After drying for $24 \mathrm{~h}$ in vacuo at room temperature, the PScoated coverslips were coated with block copolymers.

PDMS-coated coverslips were obtained by coating clean glass coverslips with a $2 \%(\mathrm{w} / \mathrm{v})$ solution of Silastic RTV adhesive [poly(dimethylsiloxane), PDMS; General Electric, Waterford, New York, USA] in THF, forming homogeneous cross-linked PDMS films after $24 \mathrm{~h}$ vacuum curing at ambient temperature. These PDMS-coated coverslips were rinsed thoroughly with doubly distilled water to remove the acetic acid produced from curing. They were then coated with block copolymers as described above.

To obtain Biomer-coated coverslips, clean glass coverslips were coated with a $2 \%(\mathrm{w} / \mathrm{v})$ solution of Solution Grade Biomer (Ethicon, Somerville, New Jersey, USA) in DMAc, forming homogeneous polyurethane films after drying for $24 \mathrm{~h}$ in vacuo at $60^{\circ} \mathrm{C}$. The dried Biomer-coated coverslips were then coated with block copolymers as described previously.

\subsubsection{Coatings for XPS}

Aluminium foil was treated in the same way as for contact angle measurements.

All (block co)polymer solutions were filtered through Teflon filters with pore size $0.5 \mu \mathrm{m}$ before the coating procedures. All (block co)polymer precoatings and coatings were clear, intact and continuous, as evidenced by optical microscopy and scanning electron microscopy (SEM).

\subsection{Determination of coating thickness}

The thickness of the coatings was determined from the weights of the uncoated and coated coverslips (measured with an analytical balance type AE 160; Mettler Instrumenten BV, Tiel, The Netherlands). After determination of the mass of the coating $(m)$, the thickness of the coating $(d)$ was calculated from

$$
d=\frac{10^{3} m}{2 A \rho_{\mathrm{PS}-\mathrm{PEO}}}
$$

in which $d$ is the coating thickness $(\mu \mathrm{m}), m$ is the mass of the coating $(\mathrm{g}), A$ is the surface area of the coating $\left(\mathrm{cm}^{2}, A=1.0 \mathrm{~cm}^{2}\right.$ for coverslips) and $\rho_{\mathrm{PS}-\mathrm{PEO}}$ is the density of the coating $\left(\mathrm{g} \mathrm{cm}^{-3}\right)$. from

The density of the coating $\left(\rho_{\mathrm{PS}-\mathrm{PEO}}\right)$ was calculated

$$
\rho_{\mathrm{PS}-\mathrm{PEO}}=x \rho_{\mathrm{PS}}+(1-x) \rho_{\mathrm{PEO}}
$$

in which $x$ is the molar fraction of styrene, $\rho_{\mathrm{PS}}=1.08$ $\pm 0.03 \mathrm{~g} \mathrm{~cm}^{-3}$ (mean $\pm \mathrm{SD}, n=5$ ), from the literature $[16-18]$ and $\rho_{\mathrm{PEO}}=1.205 \mathrm{~g} \mathrm{~cm}^{-3}$, from the literature [19].

\subsection{Transmission electron microscopy}

In order to obtain sufficient contrast between PS and PEO, or PEO-Hep microphases, ultrathin films were exposed to the vapour of an aqueous $\mathrm{OsO}_{4}$ solution $(1-3 \%, \mathrm{w} / \mathrm{v})$ at $20^{\circ} \mathrm{C}$ for $15 \mathrm{~h}$. The microstructures were observed in a Jeol JEM-200CX TEM operated at an accelerating voltage of 80 or $200 \mathrm{kV}$.

\subsection{Sessile drop contact angle measurements}

Contact angles were measured by a drop-on-plate method in a thermostatically heated contact angle cell, employing an Erma G1 apparatus. By means of a suitable syringe, a drop of water was placed on the polymer surface. A microscope equipped with a goniometer device enabled direct readings of contact angle values.

For each sample drops on six sites of the sample surface were examined at $24^{\circ} \mathrm{C}$ and the average advancing contact angles were recorded. In order to examine the effect of hydration on the surface properties of the coatings, contact angles were also measured after different exposure times of the surfaces to doubly distilled water.

\subsection{Dynamic contact angle measurements}

Dynamic advancing and receding $\left(\Theta_{\mathrm{a}}\right.$ and $\left.\Theta_{\mathrm{r}}\right)$ water contact angles were measured using the Wilhelmy plate technique $[9,20,21]$. The polymer-coated coverslips were immersed in doubly distilled water at a speed of $11 \mathrm{~mm} \mathrm{~min}^{-1}$. The temperatures of the water and the surroundings were kept at $20^{\circ} \mathrm{C}$. The surface tension of doubly distilled water $\left(\gamma_{\mathrm{Iv}}\right)$ at $20^{\circ} \mathrm{C}$ was determined by van Damme et al. [9] to be $72.6( \pm 0.5)$ $\times 10^{-3} \mathrm{~N} \mathrm{~m}^{-1}$ using completely wetting ultraclean coverslips. To obtain the wetting curves, the weight of the coverslips as a function of the immersion depth was measured with an electrobalance (model RM-2; Cahn/Ventron, Paramount, California, USA). After extrapolation of the plots obtained for the advancing and receding modes to zero immersion depth, $\Theta_{\mathrm{a}}$ and $\Theta_{\mathrm{r}}$ were calculated from

$$
\cos \Theta_{\mathrm{a}, \mathrm{r}}=\frac{g}{p \gamma_{\mathrm{lv}}}(m+\rho V)
$$

where $g$ is the local gravitational constant $\left(9.812 \mathrm{~m} \mathrm{~s}^{-2}\right), p$ is the perimeter of the sample $(p$ $=0.0484 \mathrm{~m}$ for coverslips), $\gamma_{\mathrm{Iv}}$ is the surface tension of doubly distilled water $\left(\mathrm{N} \mathrm{m}^{-1}\right), m$ is the mass of the sample $(\mathrm{kg}), \rho$ is the density of water $\left(\mathrm{kg} \mathrm{m}^{-3}\right)$ and $V$ is the volume $\left(\mathrm{m}^{3}\right)$ of the immersed sample.

The buoyancy factor $\rho V$ could be omitted by extrapolating the straight-line buoyancy slopes to the point of zero immersion depth $(V=0)$.

In order to examine the effects of hydration on the surface properties of the coatings, contact angle analysis was performed after exposure of the surfaces to doubly distilled water for periods varying from 3 to approximately $150 \mathrm{~h}$.

\subsection{X-ray photoelectron spectroscopy}

Polymers were studied either as fine powders coated on double-sided Balzers tape directly attached to the 
TABLE II Dynamic contact angles (means $\pm \mathrm{SEM}, n=4$ ) of $\mathrm{PS}_{5} \mathrm{E}_{2}$ coated on glass

\begin{tabular}{|c|c|c|c|c|}
\hline \multirow{2}{*}{$\begin{array}{l}\text { Coating } \\
\text { concentration }{ }^{\mathrm{a}} \\
(\% \mathrm{w} / \mathrm{v})\end{array}$} & \multirow{2}{*}{$\begin{array}{l}\text { Coating } \\
\text { thickness } \\
(\mu \mathrm{m})\end{array}$} & \multicolumn{3}{|c|}{ Contact angle (degrees) } \\
\hline & & Advancing & Receding & Hysteresis \\
\hline 2.0 & $5.9 \pm 1.0$ & $85 \pm 1$ & $25 \pm 1$ & $60 \pm 2$ \\
\hline 1.0 & $2.9 \pm 0.5$ & $89 \pm 1$ & $22 \pm 2$ & $67 \pm 3$ \\
\hline 0.50 & $1.0 \pm 0$ & $89 \pm 2$ & $17 \pm 2$ & $72 \pm 4$ \\
\hline 0.25 & $0.8 \pm 0.2$ & $92 \pm 1$ & $16 \pm 2$ & $76 \pm 3$ \\
\hline 0.125 & $0.5 \pm 0$ & $88 \pm 2$ & $13 \pm 2$ & $75 \pm 4$ \\
\hline 0.06125 & $<0.5$ & $88 \pm 2$ & $11 \pm 1$ & $77 \pm 3$ \\
\hline 0 & 0 & 0 & 0 & 0 \\
\hline
\end{tabular}

${ }^{a}$ Coating solution, solvent DMF- $\mathrm{H}_{2} \mathrm{O} 40: 1(\mathrm{v} / \mathrm{v})$.

spectrometer probe sample holder, or as cast films on aluminium substrates. The aluminium substrates were placed on the sample holder and transferred to the measurement chamber of a Leybold-Heraeus-type LHS-10 XPS/AES apparatus. The basic pressure in the measurement chamber was kept around $1 \times 10^{-8} \mathrm{~Pa}$, using a turbomolecular pump. $\mathrm{MgK} K_{\alpha}$ $(1253.6 \mathrm{eV})$ radiation was obtained from an X-ray tube operating at $13 \mathrm{kV}$ and $20 \mathrm{~mA}$. Each sample was investigated at a fixed glancing angle of $0^{\circ}$, corresponding to a sampling depth of approximately $5 \mathrm{~nm}$. No evidence was obtained for radiation damage to the samples during the typical timescale involved in the measurements. A dedicated Hewlett-Packard HP 1000 E-series computer system was used for spectrometer control and data handling.

To elucidate the effects of hydration on the block copolymer coatings, the coatings were hydrated for $24 \mathrm{~h}$ in doubly distilled water before the XPS measurements. The probe sample holder was constructed in such a way that by the use of liquid nitrogen the wet sample was quickly cooled to a temperature of $-185^{\circ} \mathrm{C}$ at $10^{5} \mathrm{~Pa} \mathrm{~N}_{2}$ atmosphere. Then the sample was transferred to the preparation chamber where the base pressure was around $1 \times 10^{-7} \mathrm{~Pa}$. The sample was warmed to $-80^{\circ} \mathrm{C}$ to sublimate the ice from the coating surface (water vapour pressure at $-80^{\circ} \mathrm{C}$ is approximately $10 \mathrm{mPa}$; pressure in the preparation chamber during sublimation $5 \mathrm{mPa}$ ). After approximately $4 \mathrm{~h}$ all of the ice was sublimated from the coating surface and the sample was quickly cooled to $-185^{\circ} \mathrm{C}$ just before the measurement.

All data were processed by using the standard software provided with this instrument. Under the experimental conditions used, the $\mathrm{Ag}\left(3 \mathrm{~d}_{5 / 2}\right)$ level at $368.30 \pm 0.02 \mathrm{eV}$ (Ni Fermi-edge zero) binding energy had a full width at half-maximum (FWHM) of $0.9 \mathrm{eV}$, in excellent agreement with Seah [22]. C(ls), N(ls), $\mathrm{Na}(1 \mathrm{~s}), \mathrm{O}(\mathrm{ls})$ and $\mathrm{S}(2 \mathrm{p})$ spectra, each $20 \mathrm{eV}$ wide, were measured quasi-simultaneously. The step width was $0.25 \mathrm{eV}$ for wide-scan spectra and $0.1 \mathrm{eV}$ for detailscan spectra. No smoothing procedure was used to modify the measured spectra. Before spectrum analysis, the X-ray satellite-lines were removed by the numerical method of Van Attekum and Trooster [23]. A linear background was subtracted. The leastsquares curve-fitting program used for spectrum analysis could handle Gaussian, Lorentzian and intermediate peak shapes.

\subsection{Determination of statistical significance}

The statistical significance of differences in the sessile drop contact angles and in the dynamic advancing and receding contact angles were determined using Student's $t$-test.

\section{Results and discussion}

\subsection{Coating thickness}

The surface structure of a coating may be dependent on its thickness. Using a proper adsorption or casting technique, coatings of a well-defined thickness and even monolayers may be deposited. To obtain these monolayers, it is envisaged that special solvent mixtures will have to be used. In such a mixture one of the liquids is a solvent for the block copolymer as well as for the hydrophobic substrate, whereas the other liquid is water [24]. The substrate can then be immersed for a short period into the block copolymer solution. Due to swelling of the substrate surface, the hydrophobic blocks will be anchored into the substrate, resulting in the exposure of the hydrophilic spacers coupled with antithrombotic agent to the liquid phase. This surface morphology can be possibly obtained by controlling the amount of block copolymer deposited on the substrate. When the amount of block copolymer deposited on the substrate is too high, a heterogeneous microphase separated morpho$\operatorname{logy}$ is expected. The availability of heparin at the surface will be important for the biological properties, and has to be measured.

For two samples, $\mathrm{PS}_{5} \mathrm{E}_{2}$ coated on glass and coated on PDMS, the coating thickness was determined as described above. The results obtained and the measured dynamic contact angles of $\mathrm{PS}_{5} \mathrm{E}_{2}$ coated on glass and on PDMS are summarized in Tables II and III, respectively. As can be seen from the tables, the thickness of the coatings was proportional to the block copolymer solution concentration used in the coating procedure. This proportionality seems to be independent of the type of substrate material used. By applying a block copolymer solution concentration of $2.0 \%$ $(\mathrm{w} / \mathrm{v})$, a coating with a thickness of approximately $6 \mu \mathrm{m}$ was obtained. Using this procedure the prepared coating possibly had a heterogeneous microphase separated surface structure. This hypothesis was supported by the fact that the measured $\Theta_{a}$ and $\Theta_{r} \operatorname{did}$ not change much as a function of the coating thickness. In the case of the formation of a monolayer, low values 
TABLE III Dynamic contact angles (means $\pm \mathrm{SEM}, n=4$ ) of $\mathrm{PS}_{5} \mathrm{E}_{2}$ coated on PDMS

\begin{tabular}{|c|c|c|c|c|}
\hline \multirow{2}{*}{$\begin{array}{l}\text { Coating } \\
\text { concentration }^{a} \\
(\% \mathrm{w} / \mathrm{v})\end{array}$} & \multirow{2}{*}{$\begin{array}{l}\text { Coating } \\
\text { thickness } \\
(\mu \mathrm{m})\end{array}$} & \multicolumn{3}{|c|}{ Contact angle (degrees) } \\
\hline & & Advancing & Receding & Hysteresis \\
\hline 2.0 & $5.8 \pm 2.2$ & $106 \pm 1$ & $74 \pm 4$ & $32 \pm 5$ \\
\hline 1.0 & $2.3 \pm 1.3$ & $107 \pm 2$ & $74 \pm 3$ & $33 \pm 5$ \\
\hline 0.50 & $1.8 \pm 0.6$ & $107 \pm 2$ & $78 \pm 1$ & $29 \pm 3$ \\
\hline 0.25 & $1.5 \pm 0.5$ & $106 \pm 1$ & $75 \pm 1$ & $31 \pm 2$ \\
\hline 0.125 & $0.5 \pm 0$ & $104 \pm 1$ & $79 \pm 1$ & $26 \pm 2$ \\
\hline 0.06125 & $<0.5$ & $106 \pm 2$ & $82 \pm 1$ & $24 \pm 2$ \\
\hline 0 & 0 & $110 \pm 1$ & $105 \pm 1$ & $5 \pm 2$ \\
\hline
\end{tabular}

${ }^{a}$ Coating solution, solvent DMF $-\mathrm{H}_{2} \mathrm{O} 0: 1(\mathrm{v} / \mathrm{v})$.

for $\Theta_{a}$, representative for a hydrophilic surface, would have been expected.

\subsection{Transmission electron microscopy}

In order to obtain information on the domain structure of the block copolymers in the solid state, the morphology of thin films of PS-PEO and PS-PEO-Hep was studied by TEM. Fig. 1 shows TEM micrographs of sections of thin films of $\mathrm{PS}_{5} \mathrm{E}_{2}$ and $\mathrm{PS}_{5} \mathrm{E}_{2} \mathrm{H}_{2}$, cast from $\mathrm{DMF}-\mathrm{H}_{2} \mathrm{O}(40: 1, \mathrm{v} / \mathrm{v})$ solutions and stained with $\mathrm{OsO}_{4}$ vapour. Domains of PEO-Hep blocks were observed as dark areas, whereas the matrix of PS blocks were seen as lighter areas. The hydrophilic domain structures of the $\mathrm{PS}_{5} \mathrm{E}_{2}$ and $\mathrm{PS}_{5} \mathrm{E}_{2} \mathrm{H}_{2}$ polymers showed differences. The hydrophilic domain structure of $\mathrm{PS}_{5} \mathrm{E}_{2}$ showed an inhomogeneous structure of $\mathrm{PEO}$, whereas in $\mathrm{PS}_{5} \mathrm{E}_{2} \mathrm{H}_{2}$ a

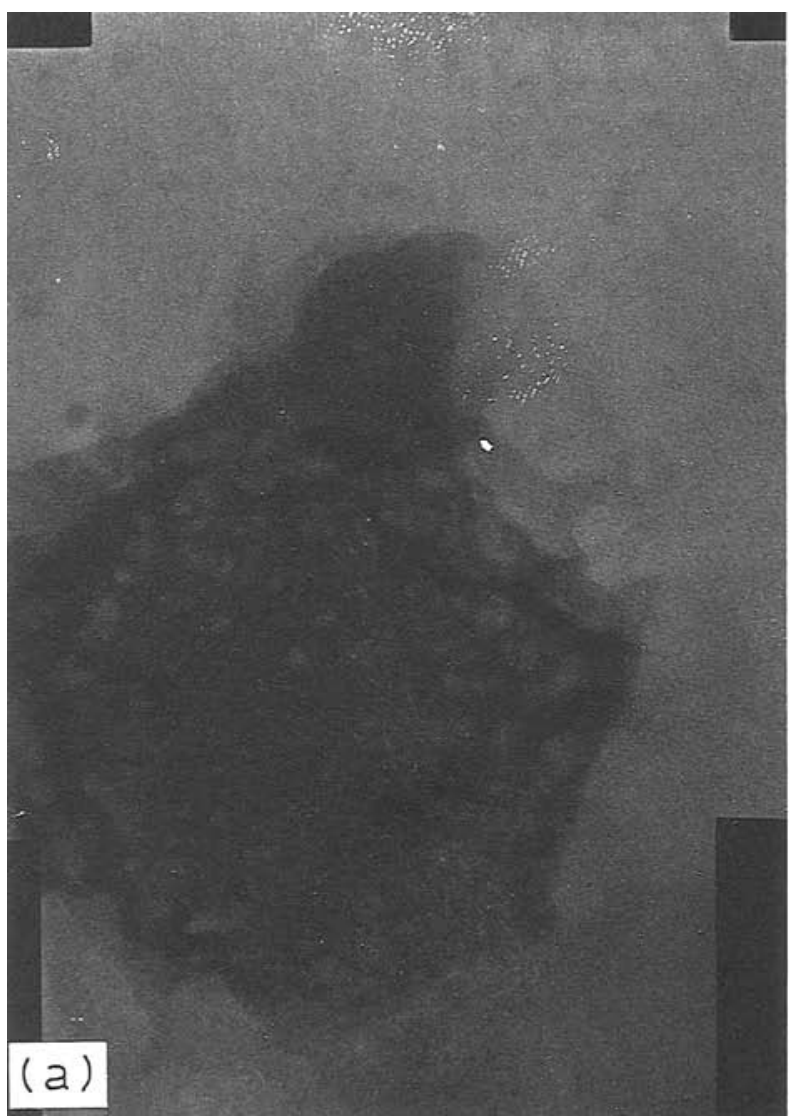

continuous dark area was observed. Table IV summarizes the TEM data obtained for all block copolymers examined

For these block copolymers, microheterophase structures were clearly observed. The PEO domains were seen as regular or irregular spots in a matrix of the PS component of the PS PEO block copolymers. Crystal et al. [25] investigated the effects of preferential solvents in the casting solution on the bulk of PS-PEO block copolymers. The morphology of a $70.0 \mathrm{~mol} \%$ PS specimen cast from ethylbenzene was examined by TEM after staining with $\mathrm{OsO}_{4}$ vapour. In this specimen larger spherical structures of the order of $300-400 \mathrm{~nm}$ were evident. Upon close inspection these regions, rich in PEO, were composed of PEO double lamellae interpenetrated with PS at interlamellar regions. Fig. 1a clearly shows this phenomenon.

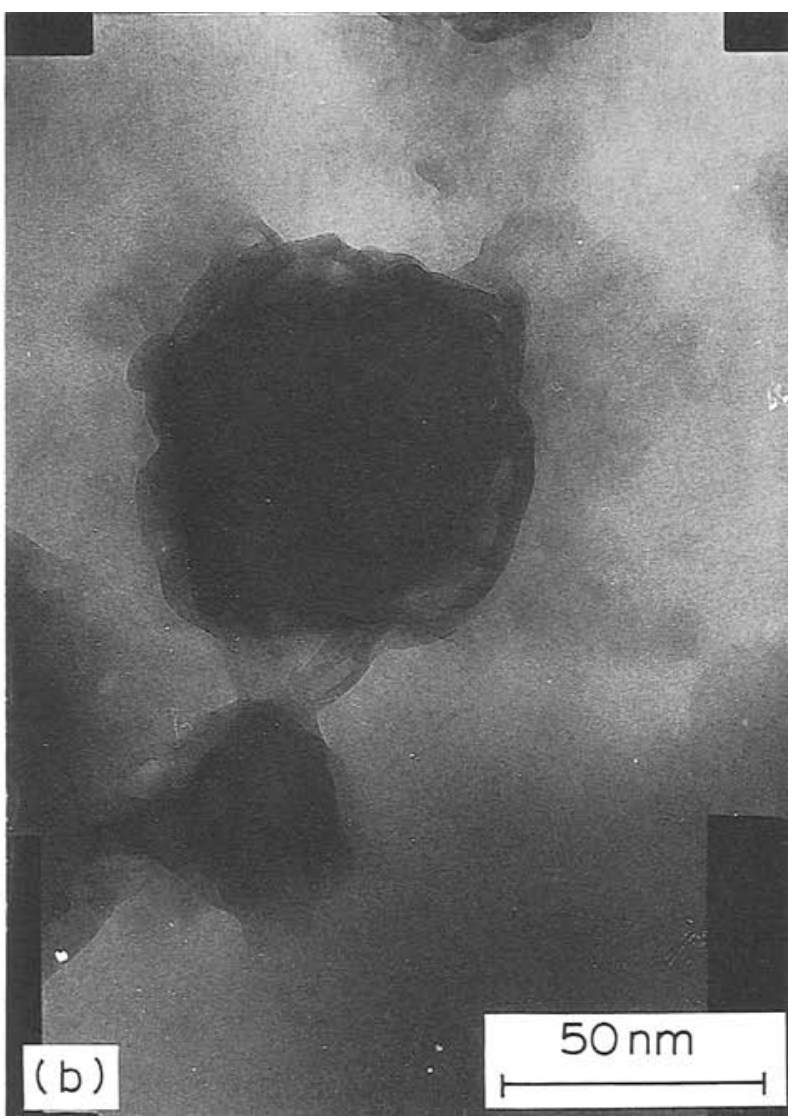

Figure 1 TEM micrographs of (a) polystyrene-poly(ethylene oxide) $\left(\mathrm{PS}_{5} \mathrm{E}_{2}\right)$ and (b) polystyrene-poly(ethylene oxide)-heparin $\left(\mathrm{PS}_{5} \mathrm{E}_{2} \mathrm{H}_{2}\right)$ block copolymers, stained with $\mathrm{OsO}_{4}$. 
TABLE IV Size and morphology of microdomains from TEM micrographs

\begin{tabular}{|c|c|c|}
\hline Polymer & $\begin{array}{l}\text { Diameter } \\
\mathrm{OsO}_{4} \text {-stained } \\
\text { domains } \\
(\mathrm{nm})^{\mathrm{a}}\end{array}$ & Remarks \\
\hline $\mathrm{PS}_{0} \mathrm{E}_{1}$ & $170 \pm 60$ & $\begin{array}{l}n=20 \text {, irregular PEO spots in PS } \\
\text { matrix }\end{array}$ \\
\hline $\mathrm{PS}_{4} \mathrm{E}_{2}$ & $180 \pm 30$ & $\begin{array}{l}n=23 \text {, regular PEO spots in PS } \\
\text { matrix }\end{array}$ \\
\hline $\mathrm{PS}_{5} \mathrm{E}_{2}$ & $130 \pm 20$ & $\begin{array}{l}n=16 \text {, regular PEO spots in PS } \\
\text { matrix }\end{array}$ \\
\hline $\mathrm{PS}_{0} \mathrm{E}_{1} \mathrm{H}_{1}$ & $480 \pm 80$ & $\begin{array}{l}n=14 \text {, ellipsoid PEO-Hep spots in } \\
\text { PS matrix, some spots connected to } \\
\text { each other }\end{array}$ \\
\hline $\mathrm{PS}_{5} \mathrm{E}_{2} \mathrm{H}_{1}$ & $90 \pm 10$ & $\begin{array}{l}n=21 \text {, regular PEO-Hep spots in } \\
\text { PS matrix, some spots connected to } \\
\text { each other }\end{array}$ \\
\hline $\mathrm{PS}_{5} \mathrm{E}_{2} \mathrm{H}_{2}$ & $70 \pm 10$ & $\begin{array}{l}n=25 \text {, regular PEO-Hep spots in } \\
\text { PS matrix }\end{array}$ \\
\hline
\end{tabular}

${ }^{a}$ Means $\pm \mathrm{SD}$.

For heparin-containing block copolymers, the PEO-Hep domains were regular or ellipsoidal spots in a matrix of PS; some PEO-Hep spots were connected with each other. Grainger and co-workers $[14,26]$ examined a PDMS-PEO-Hep block copolymer film cast from a $\mathrm{THF}-\mathrm{H}_{2} \mathrm{O}(5: 1, \mathrm{v} / \mathrm{v})$ solution by TEM after staining with $\mathrm{RuO}_{4}$ vapour. They observed domains of PEO-Hep as scattered regions approximately $10 \mathrm{~nm}$ across, interconnected by bridges of the same segment.

\subsection{Sessile drop contact angles}

The sessile drop contact angles $\left(\Theta_{a}\right)$ of coatings of block copolymers on aluminium substrates are presented in Table V. Uncoated aluminium was used as a control. For some block copolymer samples, contact angles were determined after 24 and $48 \mathrm{~h}$ hydration with doubly distilled water. It appears from Table $V$ that the surfaces of the coatings in the non-hydrated state show a moderately high $\Theta_{\mathrm{a}}$, indicating a relatively hydrophobic character. This may be explained by an enrichment of PS at the surface of the coatings.

Thomas and O'Malley [11] demonstrated by XPS that the composition of surfaces of films of PS PEO

TABLE V Sessile drop contact angles (means \pm SD, $n=6$ ) of block copolymers coated on aluminium

\begin{tabular}{lcl}
\hline Substrate & Hydration time (h) & $\begin{array}{l}\text { Contact angle } \\
\text { (degrees) }\end{array}$ \\
\hline Aluminium & 0 & $45 \pm 2$ \\
$\mathrm{PS}_{5} \mathrm{E}_{2}$ & 0 & $75 \pm 2^{\mathrm{a}}$ \\
$\mathrm{PS}_{5} \mathrm{E}_{2}$ & 24 & $67 \pm 2$ \\
$\mathrm{PS}_{5} \mathrm{E}_{2}$ & 48 & $66 \pm 3$ \\
$\mathrm{PS}_{5} \mathrm{E}_{2} \mathrm{H}_{1}$ & 0 & $66 \pm 1^{\mathrm{a}}$ \\
$\mathbf{P S}_{5} \mathrm{E}_{2} \mathrm{H}_{1}$ & 24 & $52 \pm 2^{\mathrm{a}}$ \\
$\mathrm{PS}_{5} \mathrm{E}_{2} \mathrm{H}_{2}$ & 0 & $78 \pm 1$ \\
$\mathrm{PS}_{5} \mathrm{E}_{2} \mathrm{H}_{2}$ & 24 & $55 \pm 2^{\mathrm{a}}$ \\
$\mathrm{PS}_{5} \mathrm{E}_{2} \mathrm{H}_{2}$ & 48 & $53 \pm 4^{\mathrm{b}}$ \\
\hline
\end{tabular}

${ }^{a} P \leqslant 0.005$ compared with the corresponding diblock copolymer value;

${ }^{\mathrm{b}} P \leqslant 0.01$ compared with the corresponding diblock copolymer value. block copolymers coated on aluminium substrates differed significantly from the overall bulk compositions. In all block copolymer films excesses of PS at the surfaces were observed. This phenomenon was explained in terms of differences in the solid-state surface tension of PS and PEO [27].

Barbucci et al. [28] prepared non-thrombogenic surfaces by forming stable complexes of heparin with poly(amide-amine) chains which were grafted on polyurethane and glass surfaces. These surfaces and surfaces modified by intermediate reactions, including the final heparinized surfaces, were characterized by measuring the contact angles. The final heparinized polyurethane and glass surfaces showed the lowest $\Theta_{\mathrm{a}}$. These values were significantly lower than those obtained for coatings of heparin-containing block copolymers, presented in Table V. Again, this may be explained by an excess of PS at the surface of the block copolymer coatings.

The contact angle measurements on hydrated coatings clearly showed that a change in surface hydrophobicity with hydration time took place (see Table V). The change in $\Theta_{\mathrm{a}}$ occurred in between 0 and $24 \mathrm{~h}$, whereas no further decreases were detected between 24 and $48 \mathrm{~h}$, indicating that the surfaces had equilibrated after $24 \mathrm{~h}$ hydration. During hydration water molecules penetrate into the surface, causing swelling and allowing increased relaxation/reorientation of PEO, or PEO-Hep chains. In time the hydrophilic chains will become more exposed to the surface.

\subsection{Wilhelmy plate dynamic contact angles}

During dynamic contact angle measurements water penetrates into the surface of the coating. The free volume of polymer chains is increased, which allows relaxation and restructuring of the surface, in such a way that the interfacial free energy of surfaces in contact with water is reduced. Therefore, differences in the advancing and receding contact angles are expected. Hydrophilic chains of PEO and PEO-Hep thermodynamically favour water over air interfaces and, if allowed to relax, will bury into the bulk polymer when exposed to air and expose preferentially to water when immersed in that medium. PS will behave in the opposite manner.

Multiblock copolymers of PS and PEO were synthesized by Grainger et al. [29], to study the influence of surface properties on the adsorption of albumin from aqueous solutions. Dynamic $\Theta_{\mathrm{a}}$ and $\Theta_{\mathrm{r}}$, as well as hysteresis and the effects of hydration (from 3 to $48 \mathrm{~h}$ ) on the polymers, were determined using the Wilhelmy plate technique. Contact angle hystereses of non-hydrated copolymer surfaces were a result of the mobility of the surface polymer molecules and sidechains. It was stated that in heterogeneous polymers $\Theta_{\mathrm{a}}$ represented the low-energy PS domains, whereas $\Theta_{\mathrm{r}}$ represented the high-energy PEO phase, producing the hysteresis loop. Thus, as PEO domains increased in size and number with decreasing PS content, hysteresis increased.

Fig. 2 shows the $\Theta_{\mathrm{a}}$ and $\Theta_{\mathrm{r}}$ of non-hydrated polymer surfaces coated on glass, PS, PDMS or Biomer. 


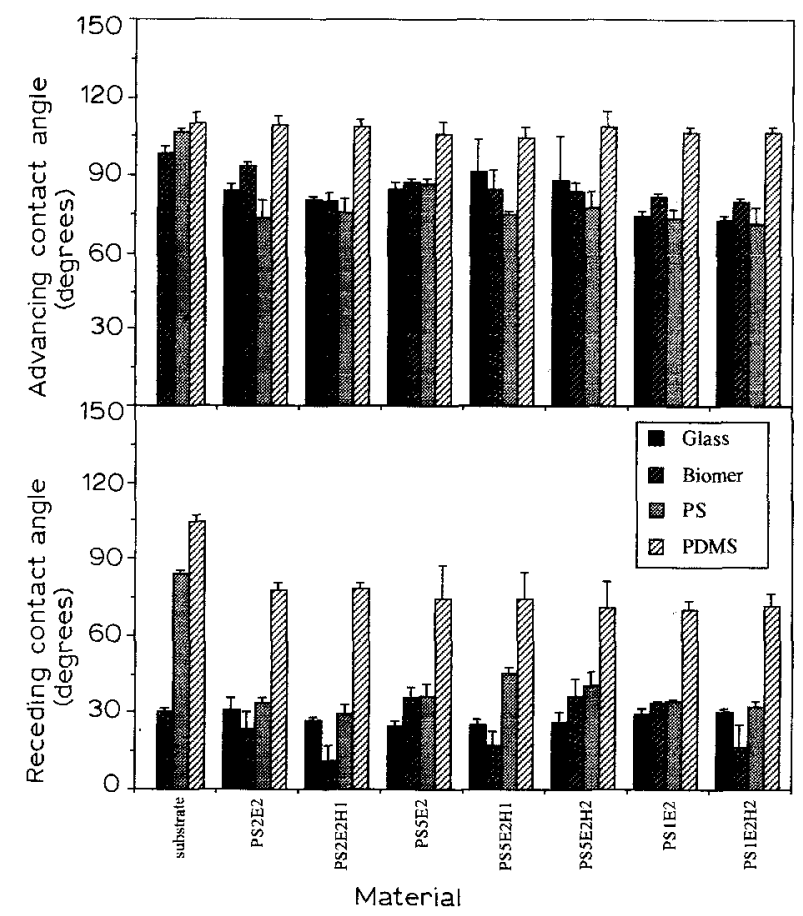

Figure 2 Dynamic advancing and receding contact angles of block copolymers coated on glass, Biomer, PS and PDMS. Mean values $\pm \mathrm{SD}$.

Uncoated, PS-, PDMS- and Biomer-coated glass coverslips were used as controls. As can be seen from Fig. 2 , it appears that the surfaces of the materials coated on glass have a moderately high $\Theta_{a}$, indicating a relatively hydrophobic character. This is possibly due to the preferential adsorption of PEO or, in the case of the heparin-containing block copolymers, PEO and/or heparin over PS as a result of the interaction of glass $-\mathrm{OH}$ groups with the $-\mathrm{O}-\mathrm{CH}_{2} \mathrm{CH}_{2}-$ backbone. A strong interaction of $\mathrm{PEO}$ with glass was also found by Fontana [30] and Kawaguchi et al. [31].

From Fig. 2 it also appears that the contact angles for block copolymers coated on glass decrease drastically after contact with water, indicating a change in the surface structure and/or composition. From the low values of $\Theta_{r}$ it seems that in contact with water more PEO and/or PEO-Hep segments of the block copolymers have been transferred to the surface and are exposed towards the aqueous phase, as postulated by Grainger et al. [29] for PDMS-PEO-Hep copolymers.

From the values of $\Theta_{\mathrm{a}}$ for block copolymers coated on glass and $\Theta_{a}$ for PS coated on glass, it can be excluded that the outermost layers of the coatings are only composed of PS. The block copolymer coatings on glass are possibly composed of a microphase separated structure in which the layer adjacent to the glass surface is enriched with PEO and/or PEO-Hep domains and the upper surface consists mainly of PS domains.

The strong interaction of PEO and/or PEO-Hep with the underlying surface can also be concluded from Fig. 2, showing that the values of $\Theta_{a}$ for block copolymers coated on PDMS resemble $\Theta_{a}$ for PS coated on glass. It seems that in this case the surfaces of the block copolymers coated on PDMS consist mainly of PS domains, whereas the PEO and/or PEO-Hep domains are buried underneath this PS layer. In contact with water the surface layer becomes more hydrophilic, exposing also PEO and/or PEO-Hep domains. Because relatively high $\Theta_{\mathrm{r}}$ values were measured, the surfaces will contain a high content of PS domains.

PS-coated coverslips coated with block copolymers showed lower $\Theta_{a}$ values than the control PS-coated glass coverslips. The decrease in $\Theta_{\mathrm{a}}$ values was even greater than that observed for the glass system, possibly due to preferential interaction of PS segments with the underlying PS substrate. The outermost layer possibly consists of a microphase separated PS-PEO/PEO-Hep structure enriched in PEO and/or PEO-Hep domains (compared with the glass system). In contact with water, $\Theta_{r}$ is lowered because of enrichment of the surface with $\mathrm{PEO}$ and/or PEO-Hep, due to swelling of PEO and/or PEO-Hep segments to allow relaxation/restructuring.

Smith et al. [32] characterized the surface properties of Biomer by measuring the dynamic water $\Theta_{a}$ and $\Theta_{r}$ using Wilhelmy plate techniques. As with most polyurethane systems, a large hysteresis for Biomer was observed. It is believed that the major portion of this hysteresis is due to the mobility of the outer chemical surface groups. When Biomer was exposed to air, the hydrophobic moieties became more prominent at the surface. In contact with water, the hydrophilic groups predominated at the surface, due to sufficient surface group mobility. The values of $\Theta_{\mathrm{a}}$ and $\Theta_{r}$ measured for Biomer coated on glass (Fig. 2) are in agreement with the data reported in the literature [32].

Biomer-coated coverslips were thus coated with the block copolymers. During the dip-coating procedure PEO and/or PEO-Hep blocks will probably show interaction with the hydrophilic soft segments, whereas PS blocks will probably have an interaction with the hydrophobic hard segments, thus creating a microphase separated PS-PEO/PS-PEO-Hep structure. This surface morphology, which will have the underlying soft/hard-segmented structure as a template, probably causes the large hysteresis found for block copolymers coated on Biomer (see Fig. 2).

Coatings with different types of PS-PEO and PS-PEO-Hep block copolymers showed no significant differences in $\Theta_{\mathrm{a}}$ or in $\Theta_{\mathrm{r}}$ when coated on one substrate, suggesting that there is not much difference in PEO or PEO-Hep content in the outermost layers of these substrates.

\subsection{Dynamic contact angles as a function of hydration time}

Figs 3-6 show $\Theta_{\mathrm{a}}$ and $\Theta_{\mathrm{r}}$ for heparin-containing block copolymers and for diblock copolymers as a function of the hydration time. The contact angles of hydrated polymer-coated glass coverslips using doubly distilled water demonstrated a considerable change in the surface character with hydration time. For the heparin-containing block copolymers coated on glass, the largest change in $\Theta_{\mathrm{a}}$ occurred between 12 and $24 \mathrm{~h}$, 


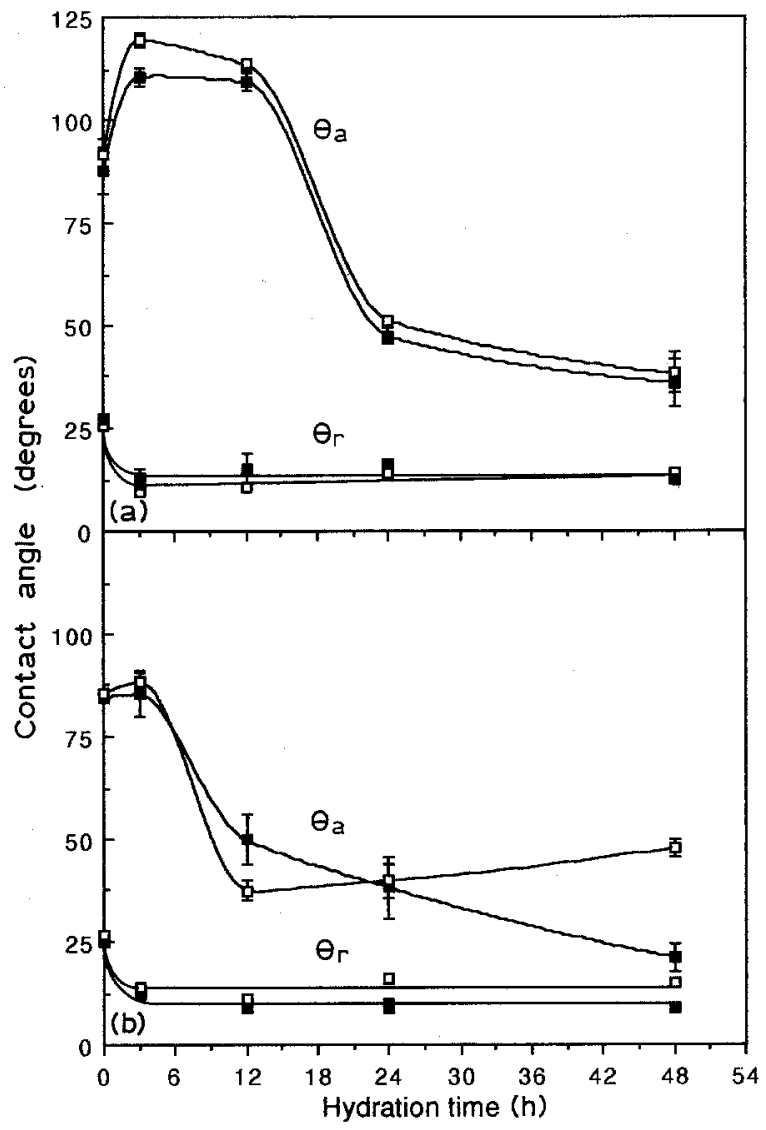

Figure 3 Dynamic advancing and receding contact angles for heparin-containing triblock and for diblock copolymer(s) coated on

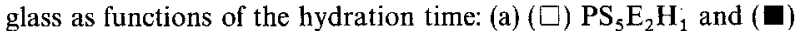
$\mathrm{PS}_{5} \mathrm{E}_{2} \mathrm{H}_{2}$, and (b) ( $\square$ ) $\mathrm{PS}_{2} \mathrm{E}_{2}$ and (E) $\mathrm{PS}_{5} \mathrm{E}_{2}$. Mean values $\pm \mathrm{SEM}$ $(n=6)$.

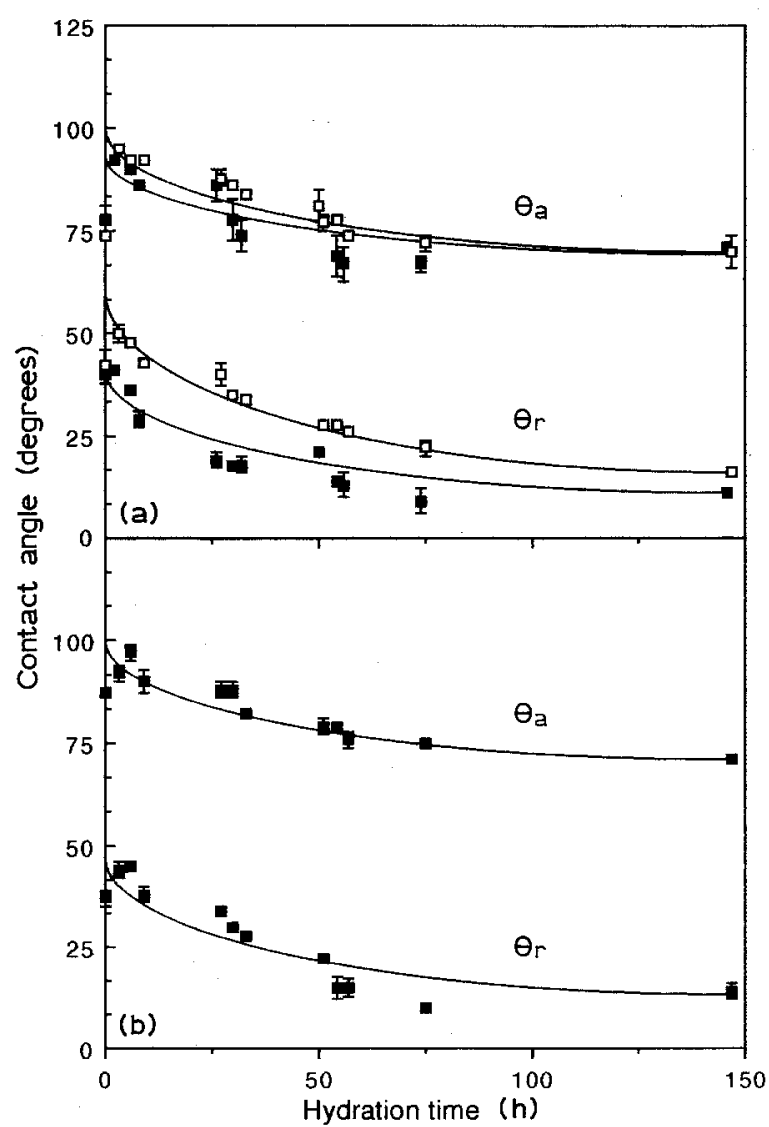

Figure 4 Dynamic advancing and receding contact angles for heparin-containing triblock and for diblock copolymer(s) coated on PS as functions of the hydration time: (a) ( $\square$ ) $\mathrm{PS}_{5} \mathrm{E}_{2} \mathrm{H}_{1}$ and (ם) $\mathrm{PS}_{5} \mathrm{E}_{2} \mathrm{H}_{2}$, and (b) (ם) $\mathrm{PS}_{5} \mathrm{E}_{2}$. Mean values $\pm \operatorname{SEM}(n=6)$.

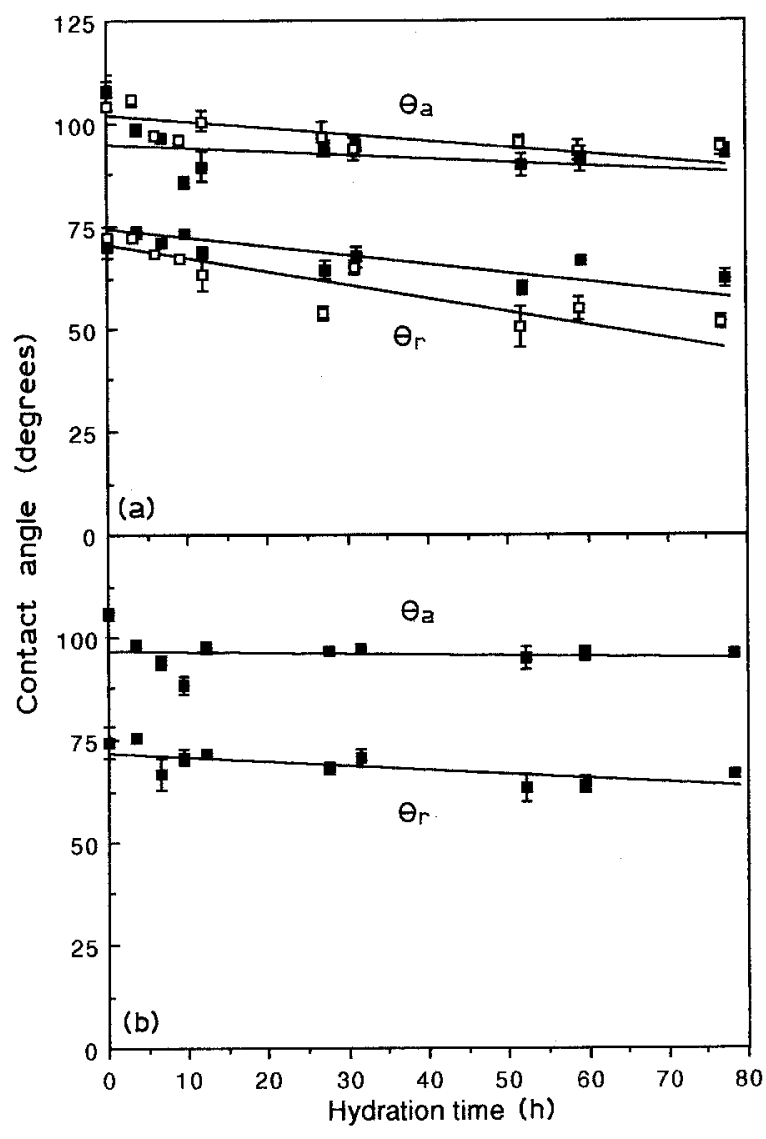

Figure 5 Dynamic advancing and receding contact angles for heparin-containing triblock and for diblock copolymer(s) coated on PDMS as functions of the hydration time: (a) ( $\square$ ) $\mathrm{PS}_{5} \mathrm{E}_{2} \mathrm{H}_{1}$ and ( $(\mathbf{\square})$ $\mathrm{PS}_{5} \mathrm{E}_{2} \mathrm{H}_{2}$, and (b) (ש) $\mathrm{PS}_{5} \mathrm{E}_{2}$. Mean values $\pm \mathrm{SEM}(n=6)$.

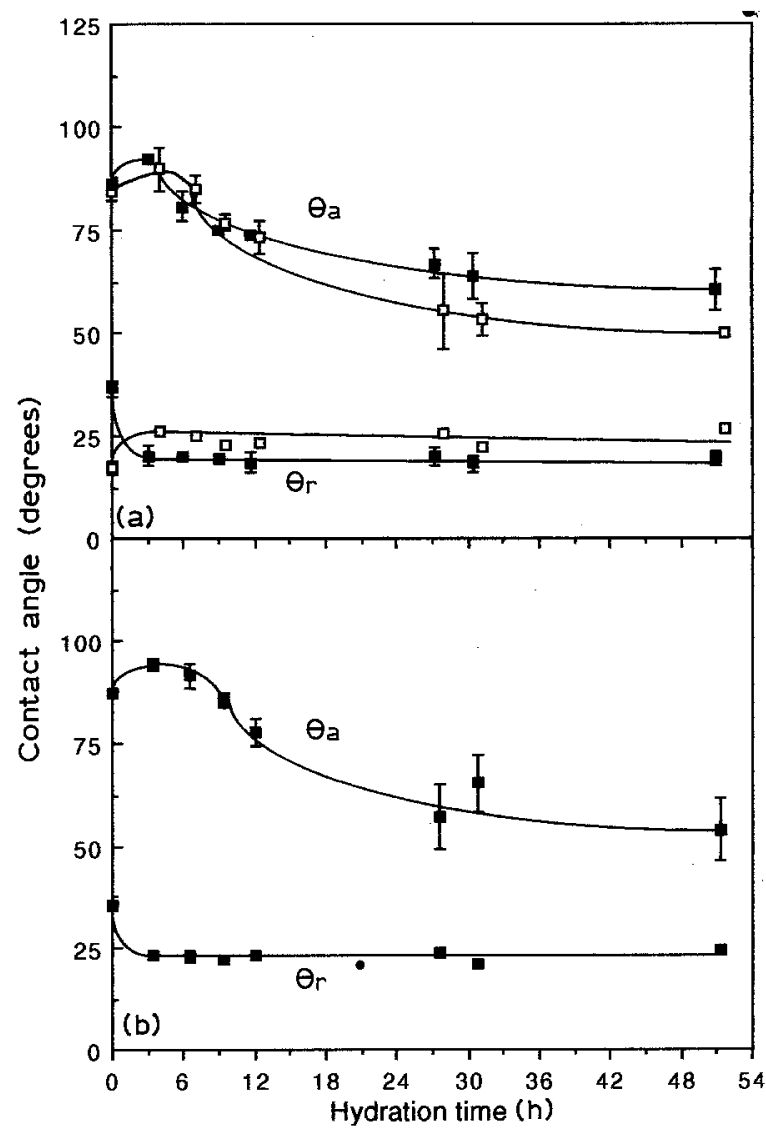

Figure 6 Dynamic advancing and receding contact angles for heparin containing triblock and for diblock copolymer(s) coated on Biomer as functions of the hydration time: (a) ( $\square$ ) $\mathrm{PS}_{5} \mathrm{E}_{2} \mathrm{H}_{1}$ and (E) $\mathrm{PS}_{5} \mathrm{E}_{2} \mathrm{H}_{2}$, and (b) (ם) $\mathrm{PS}_{5} \mathrm{E}_{2}$. Mean values $\pm \operatorname{SEM}(n=6)$. 
whereas for PS-PEO coated on glass the decrease in $\Theta_{\mathrm{a}}$ occurred between 6 and $12 \mathrm{~h}$. For both types of coatings $\Theta_{\mathrm{r}}$ decreased slightly in the first $3 \mathrm{~h}$ and remained almost constant during the following $48 \mathrm{~h}$.

For the systems of uncoated, PS- and Biomercoated glass coverslips, the observations strongly support the idea that during hydration PEO and/or PS cause the movement of PS segments to the underlying substrate while $\mathrm{PEO} / \mathrm{PEO}-\mathrm{Hep}$ segments are exposed to the water phase. Because of the reorientation of PS segments, $\Theta_{\mathrm{a}}$ decreases during hydration. From Fig. 3 it is suggested that the relaxation of heparincontaining block copolymers requires more time than that of PS-PEO, possibly due to the higher molecular weight of the PEO-Hep block segments. During the process of reorientation and relaxation, PEO and PEO-Hep block segments become more exposed to the water phase, whereas PS segments are becoming attached to the glass substrate via weak interactions between silanol groups and phenyl groups. This possible molecular weight-dependent reorientation/relaxation is not seen for the systems shown in Figs 4 and 6.

In the case of PDMS-coated glass coverslips (Fig. 5), contact angles of diblock copolymer coatings showed no change with hydration time. For the heparin-containing block copolymers there was a slight decrease in contact angles with increasing hydration time, as was also observed by Grainger [14]. The hydration time-dependent changes were minimal due to minimal water uptake by the block copolymer films. As was shown above for the non-hydrated PDMS system, the surface of block copolymer coatings on PDMS consisted mainly of PS, whereas the PEO and/or PEO-Hep domains were buried underneath the PS layer. The closed PS top layer possibly prevents water from penetrating to the deeper PEO and/or PEO-Hep domains, although there are some PEO and/or PEO-Hep domains in the outermost layer of the surface, as evidenced by a $\Theta_{\mathrm{r}}$ lower than $\Theta_{a}$ for the non-hydrated PDMS system.

\subsection{X-ray photoelectron spectroscopy}

In order to establish a firm basis for the interpretation of XPS data for heparin-containing block copolymers, it was necessary to study the homopolymers, PS$\mathrm{NH}_{2}, \mathrm{H}_{2} \mathrm{~N}-\mathrm{PEO}(4000)-\mathrm{NH}_{2}$ and heparin separately, and to determine the absolute and relative binding energies and the relative peak intensities for the different elements. The binding energies and atomic percentages of $\mathrm{C}(1 \mathrm{~s}), \mathrm{N}(1 \mathrm{~s}), \mathrm{Na}(1 \mathrm{~s}), \mathrm{O}(1 \mathrm{~s})$ and $\mathrm{S}(2 \mathrm{p})$ core levels for powders of the reference polymers, deposited on double-sided tape, are shown in Table VI.

The spectra for $\mathrm{PS}_{5}(n=2)$ showed a strong peak centred at $284.6 \mathrm{eV}$ associated with direct photoionization of $\mathrm{C}(1 \mathrm{~s})$ core levels and a low-energy satellite peak at $291.3 \mathrm{eV}$ arising from shake-up transitions $\left(\pi^{*} \leftarrow \pi\right)$ accompanying core ionization. The qualitative and quantitative analyses were in close agreement with analyses performed by others [33-37], although in our case 1.5 at $\%$ oxygen was found at the surface, arising from the presence of oxidized contaminants [38]. The measured atomic percentages of carbon and

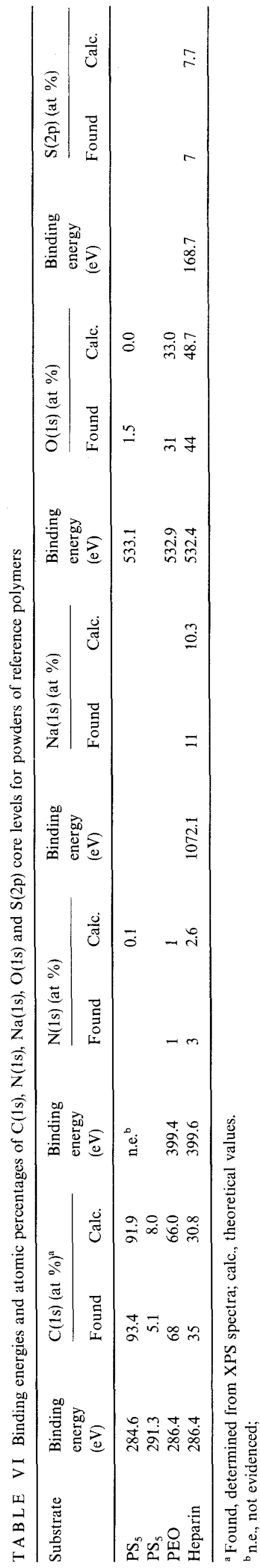


TABLE VII Binding energy shifts (means $\pm \mathrm{SD} ; \Delta \mathrm{eV}$ ) of $\mathrm{C}(1 \mathrm{~s}$ ) core levels

\begin{tabular}{lll}
\hline $\mathrm{C}(1 \mathrm{~s})$ core level & Literature data $^{\mathrm{a}}$ & Experimental $^{\mathrm{b}}$ \\
\hline $\mathrm{C}-\mathrm{C}, \mathrm{C}-\mathrm{H}(284.6 \mathrm{eV})$ & 0 & 0 \\
$\mathrm{C}-\mathrm{C}=\mathrm{O}$ & $0.8 \pm 0.1(n=2)$ & \\
$\mathrm{C}-\mathrm{O}$ & $1.7 \pm 0.2(n=29)$ & $1.8 \pm 0.2(n=11)$ \\
$\mathrm{C}=\mathrm{O}$ & $2.8 \pm 0.1(n=3)$ & \\
$\mathrm{COO}$ & $3.9 \pm 0.1(n=25)$ & $4.0 \pm 0.0(n=6)$ \\
$\mathrm{OCOO}$ & 6.0 & \\
$\pi^{*} \leftarrow \pi$ & $6.8 \pm 0.2(n=4)$ & $6.6 \pm 0.3(n=10)$ \\
\hline
\end{tabular}

${ }^{a}$ From the literature [40-45].

${ }^{\mathrm{b}}$ Experimentally observed in the polymers studied.

oxygen atoms were in agreement with calculated theoretical values, except for nitrogen atoms, which were not shown by XPS.

The spectra for $\mathrm{H}_{2} \mathrm{~N}-\mathrm{PEO}-\mathrm{NH}_{2}(n=2)$ showed single peaks for $\mathrm{C}(1 \mathrm{~s})$ core levels at $286.4 \mathrm{eV}$ and single peaks for $\mathrm{O}(1 \mathrm{~s})$ core levels at $532.9 \mathrm{eV}$. Due to the presence of amino end-groups, small peaks for $\mathrm{N}(1 \mathrm{~s})$ core levels at $399.4 \mathrm{eV}$ were also detected, corresponding to 1 at $\%$. The chemical shift of approximately $1.8 \mathrm{eV}$ for the $\mathrm{C}(1 \mathrm{~s})$ core level peak in $\mathrm{PEO}$, relative to PS, was attributed to each carbon being attached to an oxygen atom and was consistent with published data [35] (see Table VII). Both qualitative and quantitative analyses gave results that were in agreement with calculated theoretical values.

The reference spectra for heparin $(n=3)$, deposited on double-sided tape, showed several peaks at $168.7 \mathrm{eV}$ for $\mathrm{S}(2 \mathrm{p}), 286.4 \mathrm{eV}$ for $\mathrm{C}(1 \mathrm{~s}), 399.6 \mathrm{eV}$ for $\mathrm{N}(1 \mathrm{~s}), 532.4 \mathrm{eV}$ for $\mathrm{O}(1 \mathrm{~s})$ and $1072.1 \mathrm{eV}$ for $\mathrm{Na}(1 \mathrm{~s})$. Also, two peaks at $198.1 \mathrm{eV}$ for $\mathrm{Cl}(2 \mathrm{p})(0.5$ at $\%)$ and $284.4 \mathrm{eV}$ for aliphatic $\mathrm{C}(1 \mathrm{~s})(15$ at $\%)$ core levels were observed. The $\mathrm{C}(1 \mathrm{~s})(\mathrm{C}-\mathrm{C}, \mathrm{C}-\mathrm{H})$ peak was probably due to the presence of carbon-containing surface contaminants [39], whereas the $\mathrm{Cl}(2 \mathrm{p})$ peak may originate from $\mathrm{NaCl}$ contaminants. The stoichiometry of heparin as calculated from XPS peak intensities (which were corrected for the presence of aliphatic carbon) was compared with results from the literature [39] and with theoretical values, presented in Table VI. The theoretical stoichiometry was obtained by assuming a heparin structure composed of a repeating $1 \rightarrow 4$ linked disaccharide unit of 2 -sulphated iduronic acid and di- $N$-6-sulphated glucosamine $\left[\left(\mathrm{C}_{12} \mathrm{H}_{15} \mathrm{O}_{19} \mathrm{Na}_{4} \mathrm{~S}_{3} \mathrm{~N}\right)_{n}\right.$ with $\left.M_{n}=11000\right]$.

The significant differences in the XPS spectra of PS-NH $\mathrm{NH}_{2}, \mathrm{H}_{2} \mathrm{~N}-\mathrm{PEO}-\mathrm{NH}_{2}$ and heparin, i.e. the approximately $1.8 \mathrm{eV}$ chemical shift in $\mathrm{C}(1 \mathrm{~s})$ core levels, the uniqueness of the $\pi^{*} \leftarrow \pi$ shake-up peak associated with the PS component, the $\mathrm{Na}(1 \mathrm{~s})$ and $\mathrm{S}(2 \mathrm{p})$ core levels associated with heparin, coupled with the peak intensity ratios, enable an analysis of the surface composition of coatings of PS-PEO-Hep block copolymers. Grainger and co-workers $[14,26]$ studied PDMS-PEO-Hep block copolymers with angulardependent XPS. At low glancing angles large amounts of PDMS were found, and at higher angles proportional increases in PEO and heparin were observed. This indicates that in vacuo PDMS dominates the surface, although small amounts of PEO or heparin are also present, which is in agreement with data from contact angle measurements [14].

Two PS-PEO-Hep block copolymers $\left(\mathrm{PS}_{5} \mathrm{E}_{2} \mathrm{H}_{1}\right.$ and $\mathrm{PS}_{5} \mathrm{E}_{2} \mathrm{H}_{2}$ ) and the prepolymer $\left(\mathrm{PS}_{5} \mathrm{E}_{2}\right)$ were analysed by XPS as a fine powder, deposited on doublesided tape and as films cast on aluminium substrates. To elucidate the effects of hydration on the surface composition of the films, coatings were also hydrated for $24 \mathrm{~h}$ in doubly distilled water before the XPS measurements were carried out. Table VIII shows the binding energies and atomic percentages of $\mathrm{C}(1 \mathrm{~s})$, $\mathrm{N}(1 \mathrm{~s})$ and $\mathrm{O}(1 \mathrm{~s})$ core levels for powder $(n=1)$, coatings $(n=2)$ and freeze-dried hydrated coatings ( $n$ $=3$ ) of $\mathrm{PS}_{5} \mathrm{E}_{2}$, as measured by XPS. From the quantitative analysis for the powder of $\operatorname{PS}_{5} E_{2}$, it was concluded that the surface composition was almost identical to the bulk composition; the calculated theoretical values were in close agreement with measured values for atomic percentages. The chemical shift of approximately $2.1 \mathrm{eV}$ for the $\mathrm{C}(1 \mathrm{~s})$ core level peak in the $\mathrm{PEO}$, relative to $\mathrm{PS}$, was attributed to the ether linkage in the PEO backbone, although this shift was slightly larger than expected (see Table VII). The $\left(\pi^{*} \leftarrow \pi\right)$ shift of approximately $6.9 \mathrm{eV}$ corresponded to previously reported values [35]. The presence of nitrogen atoms at the surface was not evidenced by XPS.

TABLE VIII Binding energies and atomic percentages of $\mathrm{C}(1 \mathrm{~s}), \mathrm{N}(1 \mathrm{~s})$ and $\mathrm{O}(1 \mathrm{~s})$ core levels for powder and coatings of $\mathrm{PS}_{5} \mathrm{E}_{2}$

\begin{tabular}{|c|c|c|c|c|c|c|c|c|c|c|}
\hline \multirow[t]{2}{*}{ Substrate } & \multirow{2}{*}{$\begin{array}{l}\text { Binding } \\
\text { energy } \\
(\mathrm{eV})\end{array}$} & & \multicolumn{2}{|c|}{$\mathrm{C}(1 \mathrm{~s})(\text { at } \%)^{\mathbf{a}}$} & \multirow{2}{*}{$\begin{array}{l}\text { Binding } \\
\text { energy } \\
\text { (eV) }\end{array}$} & \multicolumn{2}{|c|}{$\mathrm{N}(1 \mathrm{~s})($ at $\%)$} & \multirow{2}{*}{$\begin{array}{l}\text { Binding } \\
\text { energy } \\
(\mathrm{eV})\end{array}$} & \multicolumn{2}{|c|}{$\mathrm{O}(1 \mathrm{~s})($ at $\%)$} \\
\hline & & & Found & Calc. & & Found & Calc. & & Found & Calc. \\
\hline $\mathrm{PS}_{5} \mathrm{E}_{2}$ powder & 291.5 & {$\left[\pi^{*} \leftarrow \pi\right]$} & 4.8 & 4.4 & n.e. ${ }^{b}$ & 0 & 0.1 & 533.0 & 4 & 4.5 \\
\hline $\mathrm{PS}_{5} \mathrm{E}_{2}$ powder & 286.7 & {$[\mathrm{C}-\mathrm{O}]$} & 7.2 & 8.6 & & & & & & \\
\hline $\mathrm{PS}_{5} \mathrm{E}_{2}$ powder & 284.6 & {$[\mathrm{C}-\mathrm{C}]$} & 84.0 & 82.4 & & & & & & \\
\hline $\mathrm{PS}_{5} \mathrm{E}_{2}$ coating & 291.5 & {$\left[\pi^{*} \leftarrow \pi\right]$} & 2.7 & & 399.4 & 1 & & 532.8 & 6.5 & \\
\hline $\mathrm{PS}_{5} \mathrm{E}_{2}$ coating & 288.6 & {$[\mathrm{COO}]$} & 1.6 & & & & & & & \\
\hline $\mathrm{PS}_{5} \mathrm{E}_{2}$ coating & 286.2 & {$[\mathrm{C}-\mathrm{O}]$} & 12.6 & & & & & & & \\
\hline $\mathrm{PS}_{5} \mathrm{E}_{2}$ coating & 284.6 & {$[\mathrm{C}-\mathrm{C}]$} & 75.6 & & & & & & & \\
\hline $\mathrm{PS}_{5} \mathrm{E}_{2}$ hydrated coating & 291.5 & {$\left[\pi^{*} \leftarrow \pi\right]$} & 1.1 & & 399.4 & 0.3 & & 532.8 & 22 & \\
\hline $\mathrm{PS}_{5} \mathrm{E}_{2}$ hydrated coating & 288.6 & [COO $]$ & 4.5 & & & & & & & \\
\hline $\mathrm{PS}_{5} \mathrm{E}_{2}$ hydrated coating & 286.3 & {$[\mathrm{C}-\mathrm{O}]$} & 11.9 & & & & & & & \\
\hline $\mathrm{PS}_{5} \mathrm{E}_{2}$ hydrated coating & 284.6 & {$[\mathrm{C}-\mathrm{C}]$} & 58.7 & & & & & & & \\
\hline
\end{tabular}

${ }^{\text {a }}$ Found, determined from XPS spectra; calc., theoretical values.

${ }^{b}$ n.e., not evidenced. 
The measured $\mathrm{C}(1 \mathrm{~s}), \mathrm{N}(1 \mathrm{~s})$ and $\mathrm{O}(1 \mathrm{~s})$ core levels of thin coatings of $\mathrm{PS}_{5} \mathrm{E}_{2}(n=2)$ are also shown in Table VIII. The spectra showed the characteristic $O(1$ s) peak of PEO, the shake-up satellite of PS and an easily deconvoluted triplet for the C(1s) core levels in PS and PEO. The quantitative analysis of the oxygen concentration calculated from the $\mathrm{O}(1 \mathrm{~s})$ signal corresponded with the $\mathrm{C}-\mathrm{O}$ concentration calculated from the $C(1 \mathrm{~s})$ signal. The origin of the COO signal (1.6 at $\%)$ is unknown and must be regarded as a contaminant (possible degradation of the PEO backbone, resulting in oxidation products). It was apparent from the spectra that the PEO concentration at the surface of the coating was significantly higher than would be predicted based on the knowledge of the bulk composition of the $\mathrm{PS}_{5} \mathrm{E}_{2}$ powder. The intensity of the $\pi^{*} \leftarrow \pi$ shake-up peak was also significantly lower than predicted.

The spectra of hydrated coatings of $\mathrm{PS}_{5} \mathrm{E}_{2}(n=3)$ showed the same characteristic peaks as those of nonhydrated coatings of $\mathrm{PS}_{5} \mathrm{E}_{2}$, although the intensities of the peaks were different (see Table VIII). The oxygen concentration of the hydrated coatings was higher than for the non-hydrated coatings. This was due to the presence of more PEO, or COO (of unknown origin). The intensity of the $\pi^{*} \leftarrow \pi$ shake-up peak was low for the hydrated coatings, indicating that less PS was present at the surface of the coating than for the non-hydrated coatings. Surprisingly, for the hydrated coatings the $\mathrm{C}-\mathrm{O}$ concentration (PEO) had not changed, but the $\mathrm{COO}$ concentration had increased compared with non-hydrated coatings. A possible explanation is that in contact with water PEO degrades, forming oxidized products containing COO groups.

As was also observed for non-hydrated $\mathrm{PS}_{5} \mathrm{E}_{2}$ coatings, the hydrated surfaces of $\mathrm{PS}_{5} \mathrm{E}_{2}$ coatings were significantly richer in PEO than in the bulk. The surface enrichment of PEO was slightly higher in the hydrated coatings of $\mathrm{PS}_{5} \mathrm{E}_{2}$, whereas the PS content was slightly lower than in non-hydrated coatings of $\mathrm{PS}_{5} \mathrm{E}_{2}$.

Fig. 7 shows XPS wide-scan spectra of heparincontaining block copolymers for powder, coating and hydrated coating, and Fig. 8 shows the resolved XPS

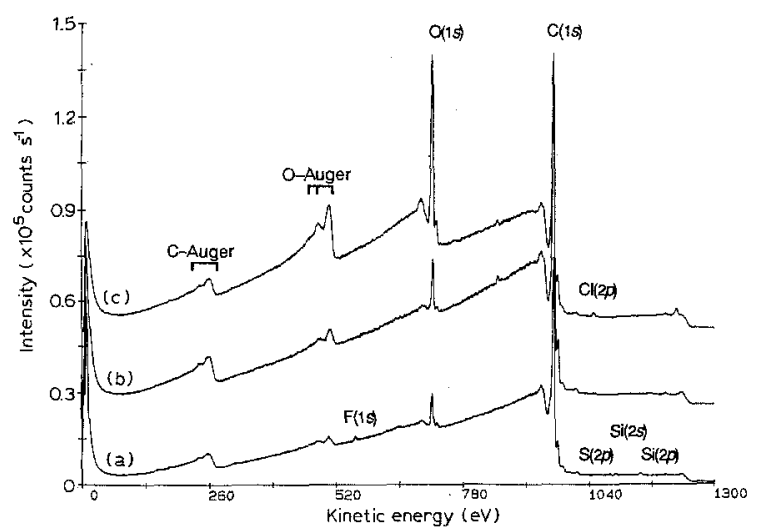

Figure 7 XPS wide-scan spectra of (a) $\mathrm{PS}_{5} \mathrm{E}_{2} \mathrm{H}_{1}$ powder deposited on double-sided tape, (b) coating of $\mathrm{PS}_{5} \mathrm{E}_{2} \mathrm{H}_{1}$ cast from $\mathrm{DMF}-\mathrm{H}_{2} \mathrm{O}$ $(40: 1, \mathrm{v} / \mathrm{v})$ solution on aluminium substrate and (c) hydrated coating of $\mathrm{PS}_{5} \mathrm{E}_{2} \mathrm{H}_{1}$.

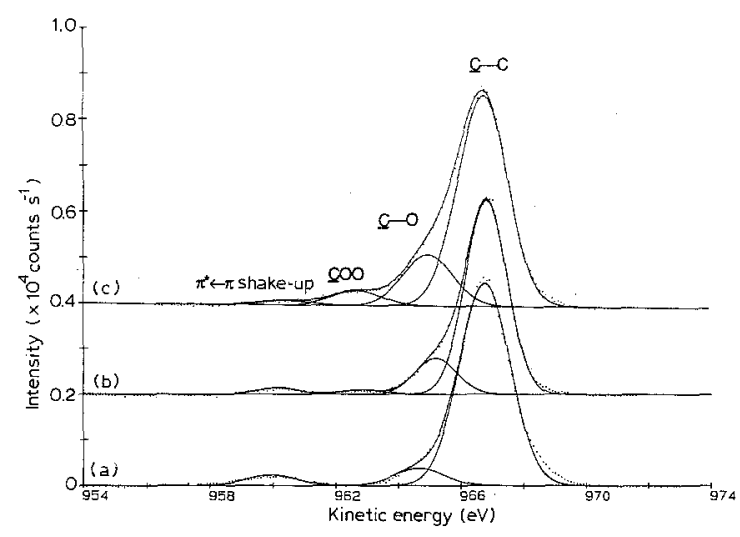

Figure 8 Resolved XPS C(1s) spectra of (a) $\mathrm{PS}_{5} \mathrm{E}_{2} \mathrm{H}_{1}$ powder deposited on double-sided tape, (b) coating of $\mathrm{PS}_{5} \mathrm{E}_{2} \mathrm{H}_{1}$ cast from $\mathrm{DMF}-\mathrm{H}_{2} \mathrm{O}(40: 1, \mathrm{v} / \mathrm{v})$ solution on aluminium substrate and (c) hydrated coating of $\mathrm{PS}_{5} \mathrm{E}_{2} \mathrm{H}_{1}$.

C(1s) spectra of heparin-containing block copolymers for powder, coating and hydrated coating. Tables IX and X list the resultant XPS data for heparincontaining block copolymers for powder, coatings and hydrated coatings, respectively. The spectra of these heparin-containing block copolymer systems exhibited signals characteristic of PS $\left(\pi^{*} \leftarrow \pi\right.$ shake-up peak), signals characteristic of PEO [the approximately $1.8 \mathrm{eV}$ chemical shift in $\mathrm{C}(1 \mathrm{~s})$ core levels] and

TABLE IX Binding energies and atomic percentages of $\mathrm{C}(1 \mathrm{~s}), \mathrm{N}(1 \mathrm{~s}), \mathrm{Na}(1 \mathrm{~s}), \mathrm{O}(1 \mathrm{~s})$ and $\mathrm{S}(2 \mathrm{p})$ core levels for powder and coatings of $\mathrm{PS}_{5} \mathrm{E}_{2} \mathrm{H}_{1}$

\begin{tabular}{|c|c|c|c|c|c|c|c|c|c|c|}
\hline Substrate & $\begin{array}{l}\text { Binding } \\
\text { energy } \\
(\mathrm{eV})\end{array}$ & $\begin{array}{l}\mathrm{C}(1 \mathrm{~s}) \\
\text { (at \%) }\end{array}$ & $\begin{array}{l}\text { Binding } \\
\text { energy } \\
\text { (eV) }\end{array}$ & $\begin{array}{l}N(1 \mathrm{~s}) \\
\text { (at \%) }\end{array}$ & $\begin{array}{l}\text { Binding } \\
\text { energy } \\
(\mathrm{eV})\end{array}$ & $\begin{array}{l}\mathrm{Na}(1 \mathrm{~s}) \\
\text { (at \%) }\end{array}$ & $\begin{array}{l}\text { Binding } \\
\text { energy } \\
(\mathrm{eV})\end{array}$ & $\begin{array}{l}\mathrm{O}(1 \mathrm{~s}) \\
\text { (at \%) }\end{array}$ & $\begin{array}{l}\text { Binding } \\
\text { energy } \\
(\mathrm{eV})\end{array}$ & $\begin{array}{l}S(2 p) \\
(\text { at \%) }\end{array}$ \\
\hline $\mathrm{PS}_{5} \mathrm{E}_{2} \mathrm{H}_{1}$ powder & 291.5 & 5.0 & 399.6 & 0.3 & 1072.4 & 0.3 & 532.9 & 6.5 & 168.9 & 0.3 \\
\hline $\mathbf{P S}_{5} \mathbf{E}_{2} \mathbf{H}_{1}$ powder & 286.7 & 6.8 & & & & & & & & \\
\hline $\mathrm{PS}_{5} \mathrm{E}_{2} \mathrm{H}_{1}$ powder & 284.6 & 79.2 & & & & & & & & \\
\hline $\mathrm{PS}_{5} \mathrm{E}_{2} \mathrm{H}_{1}$ coating & 291.5 & 3.0 & 399.4 & 1 & 1072.7 & 0.1 & 532.8 & 6.8 & 168.8 & 0.1 \\
\hline $\mathrm{PS}_{5} \mathrm{E}_{2} \mathrm{H}_{1}$ coating & 288.6 & 2.1 & & & & & & & & \\
\hline $\mathrm{PS}_{5} \mathrm{E}_{2} \mathrm{H}_{1}$ coating & 286.2 & 13.5 & & & & & & & & \\
\hline $\mathrm{PS}_{5} \mathrm{E}_{2} \mathrm{H}_{1}$ coating & 284.6 & 73.2 & & & & & & & & \\
\hline $\mathrm{PS}_{5} \mathrm{E}_{2} \mathrm{H}_{1}$ hydrated coating & 291.5 & 1.6 & 399.6 & 0.7 & n.e. ${ }^{a}$, & & 532.8 & 26.2 & 168.7 & 0.1 \\
\hline $\mathrm{PS}_{5} \mathrm{E}_{2} \mathrm{H}_{1}$ hydrated coating & 288.6 & 2.6 & & & & & & & & \\
\hline $\mathrm{PS}_{5} \mathrm{E}_{2} \mathrm{H}_{1}$ hydrated coating & 286.3 & 12.2 & & & & & & & & \\
\hline $\mathrm{PS}_{5} \mathrm{E}_{2} \mathrm{H}_{1}$ hydrated coating & 284.6 & 51.4 & & & & & & & & \\
\hline
\end{tabular}

\footnotetext{
${ }^{a}$ n.e., not evidenced.
} 
TABLE X Binding energies and atomic percentages of $\mathrm{C}(1 \mathrm{~s}), \mathrm{N}(1 \mathrm{~s}), \mathrm{Na}(1 \mathrm{~s}), \mathrm{O}(1 \mathrm{~s})$ and $\mathrm{S}(2 \mathrm{p})$ core levels for powder and coatings of $\mathrm{PS}_{5} \mathrm{E}_{2} \mathrm{H}_{2}$

\begin{tabular}{|c|c|c|c|c|c|c|c|c|c|c|}
\hline Substrate & $\begin{array}{l}\text { Binding } \\
\text { energy } \\
(\mathrm{eV})\end{array}$ & $\begin{array}{l}\mathrm{C}(1 \mathrm{~s}) \\
(\text { at } \%)\end{array}$ & $\begin{array}{l}\text { Binding } \\
\text { energy } \\
(\mathrm{eV})\end{array}$ & $\begin{array}{l}\mathrm{N}(1 \mathrm{~s}) \\
(\text { at } \%)\end{array}$ & $\begin{array}{l}\text { Binding } \\
\text { energy } \\
(\mathrm{eV})\end{array}$ & $\begin{array}{l}\mathrm{Na}(1 \mathrm{~s}) \\
(\text { at } \%)\end{array}$ & $\begin{array}{l}\text { Binding } \\
\text { energy } \\
(\mathrm{eV})\end{array}$ & $\begin{array}{l}\mathrm{O}(1 \mathrm{~s}) \\
(\text { at } \%)\end{array}$ & $\begin{array}{l}\text { Binding } \\
\text { energy } \\
(\mathrm{eV})\end{array}$ & $\begin{array}{l}S(2 p) \\
(\text { at \%) }\end{array}$ \\
\hline $\mathrm{PS}_{5} \mathrm{E}_{2} \mathrm{H}_{2}$ powder & 291.4 & 4.6 & n.e. ${ }^{\mathrm{a}}$ & & n.e. & & 533.0 & 6.0 & n.e. & \\
\hline $\mathrm{PS}_{5} \mathrm{E}_{2} \mathrm{H}_{2}$ powder & 286.7 & 7.4 & & & & & & & & \\
\hline $\mathrm{PS}_{5} \mathrm{E}_{2} \mathrm{H}_{2}$ powder & 284.6 & 80.5 & & & & & & & & \\
\hline $\mathrm{PS}_{5} \mathrm{E}_{2} \mathrm{H}_{2}$ coating & 291.2 & 3.2 & 399.4 & 1 & 1072.7 & 0.1 & 532.8 & 6.3 & 168.9 & 0.1 \\
\hline $\mathrm{PS}_{5} \mathrm{E}_{2} \mathrm{H}_{2}$ coating & 288.6 & 1.4 & & & & & & & & \\
\hline $\mathrm{PS}_{5} \mathrm{E}_{2} \mathrm{H}_{2}$ coating & 286.3 & 12.2 & & & & & & & & \\
\hline $\mathrm{PS}_{5} \mathrm{E}_{2} \mathrm{H}_{2}$ coating & 284.6 & 74.5 & & & & & & & & \\
\hline $\mathrm{PS}_{5} \mathrm{E}_{2} \mathrm{H}_{2}$ hydrated coating & 290.7 & 1.4 & 399.6 & 0.6 & n.e. & & 532.8 & 16.5 & 168.4 & 0.1 \\
\hline $\mathrm{PS}_{5} \mathrm{E}_{2} \mathrm{H}_{2}$ hydrated coating & 288.6 & 3.9 & & & & & & & & \\
\hline $\mathrm{PS}_{5} \mathrm{E}_{2} \mathrm{H}_{2}$ hydrated coating & 286.3 & 12.2 & & & & & & & & \\
\hline $\mathrm{PS}_{5} \mathrm{E}_{2} \mathrm{H}_{2}$ hydrated coating & 284.6 & 64.4 & & & & & & & & \\
\hline
\end{tabular}

${ }^{a}$ n.e., not evidenced.

only minor signals characteristic of heparin $[\mathrm{Na}(1 \mathrm{~s})$ and $\mathrm{S}(2 \mathrm{p})$ core levels]. Furthermore, Fig. 8 shows that small peaks arising from carboxylic acid groups $(\mathrm{COO})$ are found. This may be due to the presence of heparin in the outermost layer of the surface, since carboxylic acid groups are present in quantifiable amounts in the heparin molecule. Since only minor signals from $\mathrm{Na}(1 \mathrm{~s})$ and $\mathrm{S}(2 \mathrm{p})$ core levels were detected, it has to be concluded that the surfaces of coatings of heparin-containing block copolymers are very like surfaces of coatings of the prepolymer $\mathrm{PS}_{5} \mathrm{E}_{2}$. Heparin was present only at the surface in minimal amounts, as measured by XPS.

\section{Conclusions}

It was demonstrated with TEM that thin films of PS-PEO and PS-PEO-Hep block copolymers, prepared by drop coating, consist of heterogeneous microphase separated structures. The PS-PEO block copolymers contained spherical domains of $\mathrm{PEO}$ in a matrix of PS, whereas PS-PEO-Hep block copolymers had regular domains of PEO-Hep, some domains connected to each other, in a matrix of PS.

With the aid of sessile drop and Wilhelmy plate dynamic contact angle measurements, insight was provided into the hydrophilicity of the surfaces of PS-PEO and PS-PEO-Hep block copolymer coatings, which were present on different substrates. Coatings with different types of PS-PEO or PS-PEO-Hep block copolymers showed no significant differences in contact angles when coated on the same substrate, suggesting that the PEO or PEO-Hep content, respectively, in the outermost layers of these coatings was almost identical. The contact angle measurements with hydrated polymer-coated aluminium, glass, PS or Biomer systems revealed that the surfaces of the coatings became more hydrophilic during immersion in water. This is due to relaxation/reorientation, or swelling of PEO or PEO-Hep domains, respectively. This was not observed for the polymer-coated PDMS system, due to an almost closed PS top layer preventing water from penetrating.

Information about the concentrations of PEO or heparin in the top layers of coatings of PS-PEO and
PS-PEO-Hep block copolymers, respectively, on aluminium substrates was gained using XPS. XPS data for PS- $\mathrm{NH}_{2}, \mathrm{H}_{2} \mathrm{~N}-\mathrm{PEO}(4000)-\mathrm{NH}_{2}$, heparin and $\mathrm{PS}_{5} \mathrm{E}_{2}$ diblock copolymer as powder, deposited on double-sided tape, agreed well with qualitative and quantitative predictions. The XPS results also indicated that films of PS-PEO and PS-PEO-Hep block copolymers showed an enrichment of PEO segments in the outermost layers of the coatings. This effect was more pronounced for hydrated surfaces. Only small amounts of heparin were detected at the surface of coatings of PS-PEO-Hep block copolymers.

Due to the ability of PS-PEO and PS-PEO-Hep block copolymers to form microdomains, different morphologies may be observed. The morphology may change at the surface in contact with air (surface mainly composed of PS) and water (surface enriched with PEO and heparin) as indicated by contact angle measurements. This conclusion is further underlined by XPS measurements. These materials, showing a heterogeneous hydrophobic/hydrophilic/heparin surface structure, will be further evaluated as possible coatings for the improvement of the blood compatibility of polymer surfaces.

\section{Acknowledgements}

The authors thank Mr P. van Hutten and Dr D. W. Grainger for their help with TEM, which was performed partially at the VA Medical Center, Salt Lake City, Utah, USA, and Dr H. S. van Damme and Mr F. Trompetter (DSM Research) for their assistance with the contact angle measurements. The assistance of Mr J. G. A. Terlingen and Mr J. A. J. Hahnraths (DSM Research) with the XPS studies, which were performed at DSM Research, Geleen, The Netherlands, is gratefully acknowledged. Dr F. J. van der Gaag is acknowledged for critically reviewing the manuscript. This work was partially supported by NIH Grant HL-17623-14.

\section{References}

1. B. D. RATNER, ACS Adv. Chem. Ser: 199 (1982) 9.

2. A. TAKAHARA, J. TASHITA, T. KAJIYAMA, M. TAKAYANAGI and W. J. MackNight, Polymer 26 (1985) 978. 
3. Idem. ibid. 26 (1985) 987.

4. M. D. LELAH, T. G. GRASEL, J. A. PIERCE and S. L. COOPER, J. Biomed. Mater. Res. 20 (1986) 433.

5. I. VULIĆ, T. OKANO, S. W. KIM and J. FEIJEN, J. Polym. Sci., Polym. Chem. Ed. 26 (1988) 381.

6. Idem, in "Biomaterials and Clinical Applications", Vol. 7, edited by A. Pizzoferrato, P. G. Marchetti, A. Ravaglioli and A. J. C. Lee (Elsevier Science, Amsterdam, 1987) p. 491.

7. I. VULIĆ, A. J. B. LOMAN, T. OKANO, S. W. KIM and J. FEIJEN, J. Polym. Sci., Polym. Chem. Ed. 28 (1990) 1693.

8. D. W. GRAINGER, T. OKANO, S. W. KIM, D. G. CASTNER, B. D. RATNER, D. BRIGGS and Y. K. SUNG, J. Biomed. Mater. Res. 24 (1990) 547.

9. H. S. VAN DAMME, A. H. HOGT and J. FEIJEN, J. Colloid Interf. Sci. 114 (1986) 167

10. R. R. RUSSELL, in Proceedings of the Ninth International Congress on Electron Microscopy, edited by J. M. Sturgess, Microsc. Soc. Canada, Toronto, Ontario, Canada, Vol. 1 (1978) p. 488.

11. H. R. THOMAS and J. J. O'MALLEY, Macromolecules 12 (1979) 323.

12. J. J. O'MALLEY, H. R. THOMAS and G. H. LEE, ibid. 12 (1979) 996.

13. H. R. THOMAS and J. J. O'MALLEY, ibid. 14 (1981) 1316.

14. D. W. GR AINGER, PhD thesis, University of Utah, Salt Lake City (1988).

15. J. HOFFMAN, O. LARM and E. SCHOLANDER, Carbohyd. Res. 117 (1983) 328

16. G. NATTA, J. Polym. Sci. 16 (1955) 143.

17. G. NATTA, P. PINO, P. CORRADINI, F. DANUSSO, E. MANTICA, G. MAZZANTI and G. MORAGLIO, J. Amer. Chem. Soc. 77 (1955) 1708.

18. G. NATTA, Makromol. Chem. 35 (1960) 94.

19. R. L. MILLER and L. E. NIELSEN, J. Polym. Sci. 55 (1961) 643.

20. R. S. HANSEN and M. MIOTTO, J.Amer. Chem. Soc. 79 (1957) 1765 .

21. L. SMITH, D. E. DOYLE, D. E. GREGONIS and J. D. ANDrade, J. Appl. Polym. Sci. 27 (1982) 1269.

22. M. P. SEAH, in Proceedings of the IXth International Vacuum Congress Vth International Conference on Solid Surfaces, edited by J. L. De Segovia, Asoc. Esp. Vacio Sus Apl., Madrid, Spain (1983) p. 63.

23. P. M. Th. M. VAN ATTEKUM and J. M. TROOSTER, J. Electron Spectrosc. Related Phenomena 11 (1977) 363.

24. E. RUCKENSTEIN and S. H. LEE, J. Colloid Interf. Sci. 123 (1988) 170.
25. R. G. CRYSTAL, J. J. O'MALLEY and P. F. ERHARDT, Polym. Prepr. 10 (1969) 804.

26. D. W. GRAINGER, J. FEIJEN and S. W. KIM, J. Biomed. Mater. Res. 24 (1990) 403.

27. L. H. LEE, $A d v$. Chem. Ser. 87 (1968) 106.

28. R. BARBUCCI, A. BASZKIN, M. BENVENUTI, M. DE LOURDES COSTA and P. FERRUTI, J. Biomed. Mater. Res. 21 (1987) 443.

29. D. W. GRAINGER, T. OKANO and S. W. KIM, Adv. Biomed. Polym. 35229 (1987).

30. B. J. FONTANA, J. Phys. Chem. 67 (1963) 2360.

31. M. KAWAGUCHI, A. SAKAI and A. TAKAHASHI, Macromolecules 19 (1986) 2952.

32. L. M. SMITH, D. E. GREGONIS, T. R. KESSLER and D. L. COLEMAN, in "Polyurethanes in Biomedical Engineering", edited by H. Planck, G. Egbers and I. Syré (Elsevier Science, Amsterdam, 1984) p. 229.

33. D. T. CLARK, D. B. ADAMS, A. DILKS, J. PEELING and H. R. THOMAS, J. Electron Spectrosc. Related Phenomena 8 (1976) 51.

34. R. HOLM, L. MORBITZER and S. STORP, Kunststoffe 67 (1977) 11 .

35. H. R. THOMAS and J. J. O'MALLEY, Amer. Chem. Soc. 12 (1979) 323.

36. J. PEELING and D. T. CLARK, Polym. Degrad. Stability 3 (1980) 97.

37. A. LiCCiardello, O. Puglisi, L. CAlCAgno and G. FOTI, Nucl. Instrum. Methods Phys. Res. B19/20 (1987) 903.

38. A. P. PIJPERS, Private communication.

39. B. LINDBERG, R. MARIPUU, K. SIEGBAHN, R. LARSSON, C. G. GÖLANDER and J. C. ERIKSSON, J. Colloid Interf. Sci. 95 (1983) 308.

40. D. T. CLARK and H. R. THOMAS, J.Polym. Sci., Polym. Chem. Ed. 14 (1976) 1671.

41. Idem, ibid. 14 (1976) 1701.

42. Idem, ibid. 16 (1976) 791

43. A. P. PIJPERS and W. A. B. DONNERS, ibid. 23 (1985) 453.

44. K. KUGO, Y. HATA, T. HAYASHI and A. NAKAJIMA Polym. J. 14 (1982) 401.

45. R. L. SCHMITT, J. A. GARDELLA, J. H. MAGILL, L. SALVATI and R. L. CHIN, Macromolecules 18 (1985) 2675 .

Received 18 February

and accepted 30 July 1992 